\title{
Diversity and structure of the microbial community in rhizosphere soil of Fritillaria ussuriensis at different health levels
}

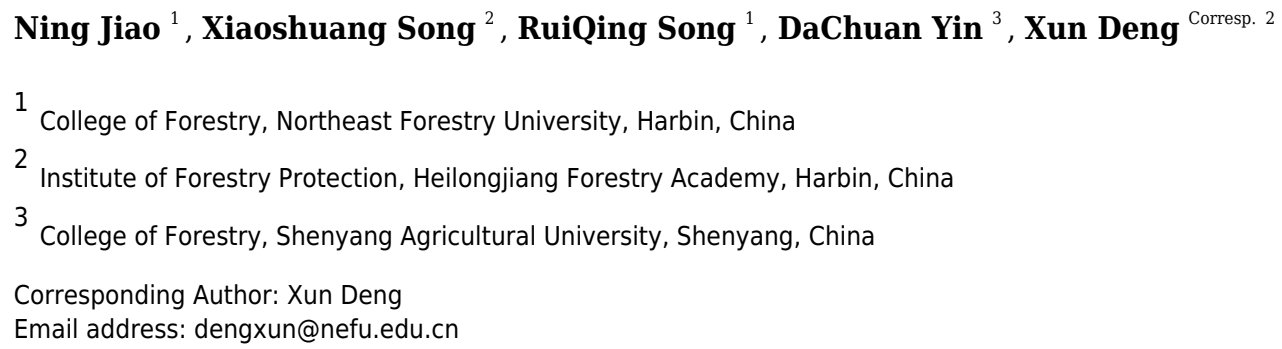

Fritillaria wilt is a kind of soil-borne disease that causes a large reduction in the yield of Fritillaria ussuriensis. The diversity and structure of the soil microbial community are important factors affecting the health of Fritillaria ussuriensis. The analysis of the microbial community in the diseased and healthy soils provided a theoretical basis for revealing the pathological mechanism and prevention of Fritillaria wilt disease. In the present study, w e sequenced the soil microorganisms from h ealthy $(H), p$ athology $(P)$ and $b$ lank $(B)$ soil samples by Illumina MiSeq. D etermined the soil physicochemical properties respectively , a nalyzed the soil microbial diversity and structure, and constructed s ingle factor cocorrelation network s among microbial genera. The results showed that Ascomycota (48.36\%) , Mortierellomycota (23.06\%), Basidiomycota (19.00\%), Proteobacteria (31.74\%), and Acidobacteria (20.95\%) were dominant in the soil . T he diversity of healthy soil $(H)$ was significantly greater than that of diseased soil samples ( $P$ and $B)(P<0.05)$. The populations of Fusarium and Humicola significantly increased in the diseased soil sample (P and B) $(P<0.05)$. RB41 $(4.74 \%)$ and Arthrobacter $(3.30 \%)$ were the most abundant genera in the healthy soil. Total nitrogen (TN), available nitrogen (AN), total potassium (TK), available potassium (AK), and inorganic salt (salt) were significantly correlated with soil microbial communities $(P<0.05)$. The relationship between fungi and the plant was mostly positive, whereas bacteria showed the opposite trend. In conclusion, the diversity and structure of the soil microbial community were closely related to the health level of Fritillaria ussuriensis. Fusarium and Humicola are the main pathogens causing Fritillaria wilt disease, while RB41 and Arthrobacter are the important indicators for maintaining the health of Fritillaria ussuriensis. Moreover, environmental factors greatly affect the abundance of soil microbial communities and the formation of soil. The interactions in microbial communities also influence the healthy growth of Fritillaria 


\section{ussuriensis.}




\section{Diversity and structure of the microbial community in}

\section{2 rhizosphere soil of Fritillaria ussuriensis at different health}

\section{3 levels}

5 Ning Jiao ${ }^{1}$, Xiaoshuang Song ${ }^{2}$, Ruiqing Song ${ }^{1}$, Dachuan Yin ${ }^{3}$, Xun Deng ${ }^{2 *}$

61 College of Forestry, Northeast Forestry University, Harbin 150040, China

72 Institute of Forestry Protection, Heilongjiang Forestry Academy, Harbin 150040, China

83 College of Forestry, Shenyang Agricultural University, Shenyang 110866, China

9 * Correspondence: dengxun@nefu.edu.cn; Tel.: +86-13836136195

10 Abstract:

Fritillaria wilt is a kind of soil-borne disease that causes a large reduction in the yield of Fritillaria ussuriensis. The diversity and structure of the soil microbial community are important factors affecting the health of Fritillaria ussuriensis. The analysis of the microbial community in the diseased and healthy soils provided a theoretical basis for revealing the pathological mechanism and prevention of Fritillaria wilt disease. In the present study, we sequenced the soil microorganisms from healthy (H), pathology (P) and blank (B) soil samples by Illumina MiSeq. Determined the soil physicochemical properties respectively, analyzed the soil microbial diversity and structure, and constructed single factor co-correlation networks among microbial genera. The results showed that Ascomycota (48.36\%), Mortierellomycota (23.06\%), Basidiomycota (19.00\%), Proteobacteria (31.74\%), and Acidobacteria (20.95\%) were dominant in the soil. The diversity of healthy soil $(\mathrm{H})$ was significantly greater than that of diseased soil samples $(\mathrm{P}$ and $\mathrm{B})(P<0.05)$. The populations of Fusarium and Humicola significantly increased in the diseased soil sample (P and B) $(P<0.05)$. RB41 $(4.74 \%)$ and Arthrobacter $(3.30 \%)$ were the most abundant genera in the healthy soil. Total nitrogen (TN), available nitrogen (AN), total potassium (TK), available potassium (AK), and inorganic salt (salt) were significantly correlated with soil microbial communities $(P<0.05)$. The relationship between fungi and the plant was mostly positive, whereas bacteria showed the opposite trend. In conclusion, the diversity and structure of the soil microbial community were closely related to the health level of Fritillaria ussuriensis. Fusarium and Humicola are the main pathogens causing Fritillaria wilt disease, while $R B 41$ and Arthrobacter are the important indicators for maintaining the health of Fritillaria ussuriensis. 
Moreover, environmental factors greatly affect the abundance of soil microbial communities and the formation of soil. The interactions in microbial communities also influence the healthy growth of Fritillaria ussuriensis.

Keywords: Fritillaria wilt disease, soil microbial community, Illumina MiSeq, health level

\section{Introduction}

Fritillaria ussuriensis Maxim., also known as Fritillaria ussuriensis, is a perennial herb belonging to the genus Fritillaria of the family Liliaceae. The dried bulb of Fritillaria ussuriensis has heat-clearing, detoxicating, cough-relieving, and phlegm-resolving effects. It is an important medicinal material in Northeast China (Park et al., 2017). Fritillaria ussuriensis is mainly distributed Changbai Mountains and the southern part of Xiaoxing'an Mountains in China (Day et al., 2014). The wild Fritillaria ussuriensis has been seriously damaged, therefore, which has been artificially cultivated on a large scale in Northeast China (Xu et al., 2013). Relevant studies have shown that Fritillaria ussuriensis should plant in black soil with sunny leeward, flat terrain, sufficient water and good drainage (Ding et al., 2018). However, Fusarium is the main cause of Fritillaria wilt, a soil borne disease, of Fritillaria ussuriensis in the long-term continuous cropping. It spreads in the soil and even causes the failure of crop production in serious cases (Baayen et al., 2001). In order to study the diversity and structure of microbial communities in the rhizosphere soil of Fritillaria ussuriensis at different health levels, we selected Fritillaria ussuriensis Planting Site of Hailin Forestry Farm which have suitable planting conditions.

It is of great importance to study the rhizosphere soils of diseased and healthy plants in long-term continuous cropping to maintain the ecological balance and provide the economic benefits for sustainable development. As far as we know, rational use or improvement of fields based on soil characteristics, soil microbial diversity and structure can manage crops more efficiently. Soil microbial community plays a key role in managing soil fertility, nutrient cycles, and plant health (Fierer et al., 2012), which are directly related to herbaceous plant health. In the soil ecosystem, the environment in close proximity to plant roots is rhizosphere, a dynamic habitat supporting resource exchange between plants and the soil environment (Peiffer et al., 2013). The microbial community in the rhizosphere soil is considered as the second genome of plants, which changes under the influence of plant roots (Philippot et al., 2013). At the same time, the diversity and colonization ability of soil microbial communities in different microhabitats affect the growth rate of pathogens and also play an important role in improving plant health (Li 
et al., 2013; Kloepper et al., 1992).

Soil conditions can indirectly reflect the level of plant health, and the occurrence of plant soil borne diseases is considered to be an unstable and unhealthy state of soil micro-ecology (Doran et al., 1996; Karlen et al., 1997). Studies have shown that changes in soil microbial community diversity and structure will affect the occurrence of soil borne diseases, soil microbial communities are very sensitive to diseased soils, and there are very few pathogens in soils with high microbial diversity (Shiomi et al., 1999; Benizri et al., 2005; Pérez-Piqueres et al., 2006). Bulluck et al. (2002) improved soil microbial diversity by applying organic fertilizers, the reproduction density of plant pathogens Phytophthora and Pythium has been greatly reduced. Reports have pointed out that the soil microbial community structure can be used to assess soil disease resistance and plant health, and some characteristic indicator microorganisms that inhibit disease can be found from soil microbial community (Gong et al., 2007). On the other hand, the soil borne diseases usually reduce soil microbial diversity, Yang et al. (2001) compared the bacterial community structure in the avocados rhizosphere soil infected by Phytophthora cinnamani and found that the bacterial community structure of healthy soil was similar, while the soil infected by Phytophthora cinnamani was significantly different, and the bacterial diversity index of the infested soil also decreased significantly. Previously, in the field evaluation of root rot disease in Fritillaria ussuriensis, we found that the abundance and diversity of soil microbial community decreased, while the population of pathogens in the healthy soil sample was quite low, which would not cause harm, indicating that the microbial community structure affected the health of Fritillaria ussuriensis (Song et al., 2016). In this study, we systematically analyzed the diversity and structure of soil microbial communities in the rhizosphere of Fritillaria ussuriensis at different health levels to illustrate the impact of changes in the microbial community on the Fritillaria ussuriensis health level.

The soil borne disease is also closely related to environmental factors (Daguerre et al., 2014). Most studies have shown that soil $\mathrm{pH}$ is negatively correlated with soil disease resistance (Rimé et al., 2003), soil viscosity can help improve plant disease resistance (Duffy et al., 1997), the form of soil nitrogen also affects soil disease resistance and ammonia nitrogen is beneficial to soil disease resistance (Tenuta et al., 2004), soil available potassium content is also negatively correlated with soil disease resistance (Xu et al., 2004). Xu et al. (2009) showed that the ginger skin rot disease was more serious in soil with high organic matter quality. Certainly, the soil physicochemical properties also directly affect the diversity and structure of soil microbial community (Doi et al., 2009). Current researches have shown that soil organic matter has been proven to be a key factor affecting the diversity and structure of soil microbial communities (Sessitsch et al., 2001). For example, Yan et al. (2000) found that soil microbial diversity was 
99 significantly related to soil $\mathrm{pH}$ and organic matter. Zhao et al. (2007) studied the relationship 100 between environmental factors and soil microbes in Chinese fir plantations and found that the 101 total number of microbes was significantly positively correlated with soil organic carbon content 102 and total nitrogen content. There have been a lot of researches on the direct influence of

103

104

105

106

107

108

109

110

111

112

113

114

115

116

117

118

119

120

121

122

123

124

125

126

127

128

129

130

131

environmental factors on microorganisms, but there is little research on the correlation between environmental factors and soil microorganisms in the plant pathological process. What are the main factors affecting the microbial diversity in rhizosphere soil of Fritillaria ussuriensis at different health levels, and how their interaction mechanism has not been reported. The solution of these problems will be of great significance to the use of microbial diversity to regulate the soil micro-ecosystem and improve the disease resistance of Fritillaria ussuriensis.

\section{Materials and methods}

\section{Site depiction and sampling}

The experiment location is at the Planting Site, in which Fritillaria ussuriensis is cultivated $\left(\mathrm{N} 44^{\circ} 89^{\prime}-44^{\circ} 88^{\prime}\right.$, E $129^{\circ} 30^{\prime}-129^{\circ} 31^{\prime}$ ), in Hailin Forestry Farm, Mudanjiang City, PRC. At the Changbai Mountains, this site is the key planting base for crops in Northeast China. The area has monsoon and middle-latitude climates, with a yearly mean temperature of $2.2^{\circ} \mathrm{C}$ and a yearly mean rainfall of $550 \mathrm{~mm}$. The persistent sequential cropping was employed in the plantation, in which the average altitude is $550 \mathrm{~m}$, the soil is meadow dark brown soil, the average soil water content is $24.55 \%$, the average temperature of the $0 \sim 5 \mathrm{~cm}$ soil layer is $21.6^{\circ} \mathrm{C}$, the average soil density is $1.54 \mathrm{~g} / \mathrm{cm}^{3}$, and the average soil porosity is $42.01 \%$. There is 30 years history of artificial cultivation in Planting Site of Fritillaria ussuriensis, the total cultivation area is nearly $2 \mathrm{~km}^{2}$. The same agronomic management practices and fertilization system were adopted at the experimental site, but years of continuous cropping resulted in serious soil borne diseases including wilt disease. Through the preliminary investigation, we found that the wilt diseases severity of Fritillaria ussuriensis in different cultivation plots was different (Figure 1). The growth cycle on aboveground parts of the Fritillaria ussuriensis is from April to June, therefore, the time of our investigation and sampling was in late May 2018 (late spring). When Fritillaria ussuriensis wilt disease occurs, bulbs rotted and turned black underground, and the aboveground plants appeared withered, obvious patches were formed on the soil surface of Fritillaria ussuriensis (pathology soil). The wilt disease continued to develop, and obvious empty window plots were formed in the second year (blank soil), while healthy plots grow vigorously, and there are no wilting patches and blank plots (healthy soil). Finally we distinguished and collected rhizosphere soil samples (healthy, pathology and blank soil) with

Peer) reviewing PDF | (2021:07:64224:1:2:NEW 19 Nov 2021) 
132

133

134

135

136

137

138

139

140

141

142

143

144

145

146

147

148

149

150

151

152

153

154

155

156

157

158

159

160

161

162

163

164

165

different health levels according to the pathological condition of Fritillaria ussuriensis wilt disease at the the Planting Site in Hailin Forestry Farm (Figure 2). The sampling method was as follows: we used the shovel to dig the soil profile at $15 \mathrm{~cm}$ depth, collecting the rhizosphere soil that was not removed after shaking, and then transferred it into sterile sample bags for the experiment. 10 sampling points in planting plots with different health levels were randomly selected respectively, after mixing the soil samples with the same health level, 6 repeated treatments were collected for each of the 3 different healthy levels soil samples (healthy, pathology and blank soil) respectively, of which 3 repeated treatments were used for soil fungal sequencing and the other 3 were used for soil bacterial sequencing, for a total of $18(3 \times 6=18)$ soil samples. All samples were homogenized thoroughly through a 2-mm sieve, transferred to the lab on ice, and afterwards reserved at $-80{ }^{\circ} \mathrm{C}$ for Illumina MiSeq. Meanwhile, the samples used to determine the soil physicochemical properties were stored in a dry place after air-drying (Collignon et al., 2011; Shanmugam et al., 2011; Uroz et al., 2016).

\section{Determination of soil physicochemical properties}

Soil $\mathrm{pH}$ was determined in a soil-to-water $(1: 2.5, \mathrm{~W} / \mathrm{V})$ mixtures of dry soil and distilled water using a HACH HQ30d pH meter (BANTE, Shanghai, China). Soil organic matter (OM) was determined by the potassium dichromate heating method. Total nitrogen $(\mathrm{TN})$ content was measured with Kjeldahl digestion and distillation azotometry (Kjeldahl distillation unit K9840, Shandong, China). Available nitrogen (AN) content was measured by $\mathrm{MgO}$ steam distillation method. Total phosphorus (TP) content was measured by the Mo-Sb colorimetric method. Available phosphorus (AP) content was measured by lixiviating-molybdenum blue colorimetry after extraction with $0.5 \mathrm{M} \mathrm{NaHCO} 3(\mathrm{pH}=8.5)$ for $30 \mathrm{~min}$. Total potassium (TK) content was measured by sodium hydroxide fusion-flame spectrophotometer method and available potassium (AK) content was measured by NH4OAc extraction-flame spectrophotometer method (flame photometer FP6410, Shanghai, China). Total soluble salt (salt) was determined by residue weighing method (set dry soil to distilled water $=1: 5, \mathrm{~W} / \mathrm{V})$.

\section{Soil DNA abstraction, PCR enlargement, and Illumina MiSeq sequence}

The entire soil DNA was abstracted via the E.Z.N.A ${ }^{\circledR}$ soil DNA Kit (Omega BioTek, America). NanoDrop ND-2000C (Thermo, America) was employed to identify the DNA level and purity, while $1 \%$ gel electrophoretic method was adopted to assess the quality of DNA (Chen et al., 2018; Zhou et al., 2016). The primer sets including ITS1F (5'CTTGGTCATTTAGAGGAAGTAA-3') and ITS2R (5'-GCTGCGTTCTTCATCGATGC-3') were selected to target the ITS1-ITS2 region for the characterization of fungal communities. 338F (5'-ACTCCTACGGGAGGCAGCAG-3') and 806R

$\left(5^{\prime}-\right.$ GGACTACHVGGGTWTCTAAT-3') primers were adopted for the amplification of the V3-V4 
166

167

168

169

170

171

172

173

174

175

176

177

178

179

180

181

182

183

184

185

186

187

188

189

190

191

192

193

194

195

196

197

198

hyper variant areas for the bacterium 16S rRNA gene (Mori et al., 2014; Xu et al., 2016). The reactive activities were completed in triplicate via a $20 \mu \mathrm{L}$ reactive mixed solution, involving 4 $\mu \mathrm{L} 5 \times$ FastPfu Buffer, $2 \mu \mathrm{L} 2.5 \mathrm{mM}$ dNTPs, $0.8 \mu \mathrm{L}$ every primer $(5 \mu \mathrm{M}), 0.4 \mu \mathrm{L}$ FastPfu Polyase, $10 \mathrm{ng}$ template DNA, $0.2 \mu \mathrm{L}$ of BSA, and $11.6 \mu \mathrm{L}$ of redistilled water (Wang et al., 2017; Fu et al., 2019). The prerequisites of amplified PCR: posterior to the incipient denaturating at $95{ }^{\circ} \mathrm{C}$ for 3 minutes, PCR was completed for 27 cycles at $95{ }^{\circ} \mathrm{C}$ for 30 seconds, annealed at $55{ }^{\circ} \mathrm{C}$ for 30 seconds, elongated at $72{ }^{\circ} \mathrm{C}$ for 45 seconds, and an eventual elongation at $72{ }^{\circ} \mathrm{C}$ for 10 minutes (PCR: ABI GeneAmp ${ }^{\circledR}$ 9700, USA). The PCR results were treated with purification via a PCR Purifying Kit (Axygen Bio, America). QuantiFluor ${ }^{\mathrm{TM}}$-ST (Promega, America) was employed for quantitation determination. Based on the requirements of sequencing, specimens were gathered proportionally, and a FastPfu database was built. Eventually, the sequencing of the purification libraries were realized via the Illumina MiSeq (TruSeqTM DNA Specimen Preparation Kit, America) (Yang et al., 2017).

\section{Bioinformatics analysis}

Posterior to the removing of the adapters and primer sequences, original sequences were merged as per the distinctive stripe code via QIIME (Caporaso et al., 2010). The split sequences for every specimen were assembled via FLASH 1.2.7 (Magoc et al., 2011), and short sequences (Seq $<200 \mathrm{bp}$ ) and low-quality sequences $(\mathrm{Q}<0.5)$ were filtered out. The UCHIME approach was adopted for the removal of chimera sequences (Patrick et al., 2017). The UPARSE 7.1 arithmetic with a 97\% sequential similarity threshold (St) was employed to acquire OTUs (Edgar. 2013). The UNITE database 7.0 was used to annotate fungal OTUs (Kõljalg et al., 2013), and the RDP database (version 9) was employed to classify bacterial OTUs (Wang et al., 2007), with the confident liminal value of $80 \%$. The alpha variety assay was completed via Mothur 1.30 (Buée et al., 2009). Based on the Bary-Curtis algorithm, the beta diversity was analyzed using PCoA (Lozupone et al., 2006). The diversity in the microbiological population was contrasted via AMOVA (Analysis of molecular variance) (Meirmans. 2006).

\section{Network analysis}

Divided healthy, pathology and blank soil samples into 3 groups, and comprehensively analyzed. The top 25 abundant fungal and bacterial OTUs were selected from the soil samples. NetworkX was used to obtain the related information from different genera and construct interaction networks (Klarner et al., 2016). The Random Matrix Theory (RMT) was employed to automatically identify the appropriate similarity threshold $(\mathrm{St})$ before network construction. At last, the JavaScript software was used to create the single-factor association network. 
199

200

201

202

203

204

205

206

207

208

209

210

211

212

213

214

215

216

217

218

219

220

221

222

223

224

225

226

227

228

\section{Statistical analyses}

SPSS 22.0 (IBM, America) was used for statistic assay. The one-way ANOVA and the Duncan's $(\alpha=0.05)$ test were adopted to contrast the soil physicochemical properties and microbial level and diversity (Halifu et al., 2019). Pearson's correlative was adopted for the establishment of an association among microbe genera, environment factors, and alpha variety (Zhou et al., 2017).

\section{Sequence registration numbers}

The sequence data were deposited in the NCBI Sequence Read Archive (SRA) database with the accession number of SRR13288220-237.

\section{Results}

\section{Soil physicochemical properties}

The soil physicochemical properties of Fritillaria ussuriensis at different health levels are summarized in Table 1. The average $\mathrm{pH}$ in diseased soil ( $\mathrm{P}$ and $\mathrm{B}$ ) was significantly lower than that in healthy soil $(\mathrm{H})(P<0.05)$. There was no significant difference in $\mathrm{pH}$ between pathology and blank samples, indicating that the soil $\mathrm{pH}$ had a lower correlation with the severity of the disease. The content of organic matter $(\mathrm{OM})$ was the highest in the blank sample $(P<0.05)$. Moreover, the contents of total nitrogen (TN), available nitrogen (AN), total phosphorus (TP), and available phosphorus (AP) increased significantly and then decreased slightly with increasing the severity of disease $(\mathrm{H} \rightarrow \mathrm{P} \rightarrow \mathrm{B})$, while the contents of total potassium (TK), available potassium $(\mathrm{AK})$, and total soluble salt (Salt) increased significantly $(P<0.05)$.

\section{Diversity of microbial community}

A total of 451644 and 399003 valid fungal and bacterial sequences, respectively, were obtained from 18 healthy, pathology, and blank soil samples, with the average sequence lengths of $240.83 \mathrm{bp}$ for fungi and $417.52 \mathrm{bp}$ for bacteria. The microbial sequences of soil samples were clustered into 1810 fungal and 3737 bacterial OTUs at the 97\% identity threshold after splitting and removing redundancy. Valid sequences were randomly sampled, and the OTUs from the extracted sequences were used to construct the rarefaction curves (Figure S1). The rarefaction curves of fungal and bacterial OTUs changed smoothly, which indicates that the information about microbes from the samples was fully obtained. This confirms the validity of the study on soil fungal and bacterial communities. 
229

230

231

232

233

234

235

236

237

238

239

240

241

242

243

244

245

246

247

248

249

250

251

252

253

254

255

256

257

258

259

260

261

The Venn diagrams showed the OTU level for the microbial community of soil samples (Figure 3). The number of fungal OTUs in healthy samples was the highest, while blank samples had the lowest number. But the distribution of bacterial OTUs was the opposite of fungal OTUs. The number of bacterial OTUs was the highest in blank samples, while it was the lowest in healthy samples. The highest number of OTUs was found in healthy samples, for both fungal and bacterial communities, with 53 and 19 OTUs, respectively. The number of shared OTUs in all samples was the highest, with $50.77 \%$ of fungal OTUs and $80.06 \%$ of bacterial OTUs. The above-mentioned distribution of OTUs showed that the fungal OTUs level in pathology samples was more similar to that in blank samples, and there was a significant difference in OTUs compared with Healthy samples, while the bacterial OTUs level was found to be similar in all samples.

ANOVA for the $\alpha$ diversity of soil samples at different health levels indicated the coverage for soil fungal samples with coverage over $99 \%$ and close to $98 \%$ for soil bacterial samples, which coincided with rarefaction curves of OTUs (Table 2). The Shannon index of fungal and bacterial communities decreased significantly and then increased with increasing the severity of disease $(\mathrm{H} \rightarrow \mathrm{P} \rightarrow \mathrm{B})(P<0.05)$. The Simpson index of fungal communities in healthy samples was significantly higher than that in diseased soil ( $\mathrm{P}$ and $\mathrm{B})$, while it hardly varied for the bacterial community during the pathological process of Fritillaria ussuriensis $(P<0.05)$. In the stage of healthy to pathology, the Ace index and Chao index of fungal and bacterial communities decreased slightly, while the difference between pathology and blank was not significant. These findings showed that the diversity of fungal and bacterial communities in pathology samples was lower than in healthy or blank samples. However, there was no significant difference in diversity between healthy and blank samples.

\section{Soil microbial community structure and composition}

To further compare the variations in the structure of fungal and bacterial communities in healthy, pathology, and blank samples, based on the Bary-Curtis algorithm, the principal coordinate analysis (PCoA) was employed (Figure 4). Diseased samples (P and B) were separated from the healthy samples, indicating large differences in the structure of microbial communities at different health levels. In addition, the degree of dispersion in fungal communities between pathology and blank samples were smaller, on the contrary, the bacterial communities were larger, suggesting that differences in the structure of fungal and bacterial communities between diseased samples (P and B).

To verify the differences observed in fungal and bacterial communities at different health 
262 levels, the relative abundances of different phyla and genera from the rhizosphere soil samples 263 were compared (Figure 5, 6). Average OTUs of 9 samples of fungus were classified into 13 264 phyla, 35 classes, 80 orders, 195 families, 325 genera, and 476 species. The phyla of fungi

265

266

267

268

269

270

271

272

273

274

275

276

277

278

279

280

281

282

283

284

285

286

287

288

289

290

291

292

293

mainly included Ascomycota $(48.36 \%)$, Mortierellomycota $(23.06 \%)$, and Basidiomycota (19.00\%), accounting for more than $90 \%$ of the abundance. The abundance of Ascomycota was the highest among all samples at different health levels and almost similar in healthy and blank samples, with a significant increase in the blank sample. The abundance of Mortierellomycota increased significantly in diseased samples ( $\mathrm{P}$ and $\mathrm{B}$ ), but the difference was not significant between pathology and blank samples. The abundance of Basidiomycota decreased significantly

with increasing the severity of disease $(\mathrm{H} \rightarrow \mathrm{P} \rightarrow \mathrm{B})$, with the lowest abundance in the blank sample. Average OTUs of 9 samples of bacteria were classified into 34 phyla and 652 genera, including mainly Proteobacteria (31.74\%), Acidobacteria (20.95\%), Actinobacteria (14.11\%), Chloroflexi (8.52\%), Bacteroidetes (6.64\%), Gemmatimonadetes (5.48\%), Patescibacteria (2.97\%), Firmicutes (2.68\%), Verrucomicrobia (2.08\%), Rokubacteria (1.37\%), and Latescibacteria $(0.56 \%)$. We found higher abundances of Proteobacteria, Gemmatimonadetes, and Firmicutes in diseased samples ( $\mathrm{P}$ and $\mathrm{B}$ ). The abundance of Acidobacteria decreased significantly with increasing the severity of disease $(\mathrm{H} \rightarrow \mathrm{P} \rightarrow \mathrm{B})$, while the abundances of Chloroflexi and Verrucomicrobia were the highest in the healthy sample.

To further study the difference in the composition of the soil microbial community at different health levels, the top 7 fungal and 15 bacterial genera with high abundances were selected from the fungal and bacterial communities in healthy, pathology, and blank samples. The difference in the relative abundance at the genus level indicated that Mortierella, Fusarium, Leucosporidium, Mrakia, Guehomyces, Humicola, and Ilyonectria were members of the fungal genera with higher abundances, among which Mortierella exhibiting the highest abundance (22.86\%). Compared with the Healthy sample, the abundance of Mortierella increased significantly in diseased samples ( $\mathrm{P}$ and $\mathrm{B}$ ). The abundances of Fusarium and Humicola increased significantly with increasing the severity of disease $(\mathrm{H} \rightarrow \mathrm{P} \rightarrow \mathrm{B})$, with the blank sample having the highest abundance $(15.49 \%$ and $5.60 \%$, respectively). On the contrary, the abundances of Mrakia and Guehomyces decreased significantly, with the highest abundance in the healthy sample and more abundance and variation in the bacterial community compared with the fungal community. The highest abundances of RB41 (4.74\%) and Arthrobacter (3.30\%) were found in the healthy sample. With increasing the severity of disease $(\mathrm{H} \rightarrow \mathrm{P} \rightarrow \mathrm{B})$, the abundance 
294

295

296

297

298

299

300

301

302

303

304

305

306

307

308

309

310

311

312

313

314

315

316

317

318

319

320

321

322

323

324

325

326

decreased significantly. The relative abundances of Sphingomonas, Bryobacter, Gemmatimonas, Bacillus, Ellin6067, Pedobacter, Acidothermus, and Acidibacter in diseased samples (P and B) were significantly higher than that in healthy samples. Furthermore, the highest abundances of Bryobacter, Acidibacter, Pseudomonas, Massilia, and Haliangium were found in pathology samples.

\section{The relationships between the diversity of soil microbial communities and soil properties}

Pearson's correlation analysis showed that AN and AP were significantly negatively correlated with the Shannon index in the fungal community but significantly positively correlated with the Simpson index $(P<0.05)$ (Table 3$)$. In the bacterial community, TP and AP were significantly negatively correlated with Shannon index, Ace index, and Chao index, with $\mathrm{pH}$ having a significantly positive correlation with Chao index, while AN was significantly negatively correlated with Chao index $(P<0.05)$.

About 30 genera of fungal and bacterial communities from rhizosphere soils were significantly different at different health levels. The correlations between the abundances of these genera and $\mathrm{pH}, \mathrm{OM}, \mathrm{TN}, \mathrm{AN}, \mathrm{TP}, \mathrm{AP}, \mathrm{TK}, \mathrm{AK}$, Salt, and microbial diversity were explored using Pearson's correlation analysis (Figure 7). In fungal genera, Thelebolus was significantly negatively correlated with $\mathrm{AN}, \mathrm{TN}, \mathrm{TP}$, and AP $(P<0.05)$. Ilyonectria, Acremonium, Cadophora, Gibberella, Mrakia, Guehomyces, and Tetracladium were negatively correlated with TK, AK, AN, Salt, and Simpson index $(P<0.05)$. Moreover, Leucosporidium was significantly positively correlated with AN, TP, AP, and Simpson index, while there was a significantly negative correlation between $\mathrm{pH}$ and Shannon index $(P<0.05)$. Penicillium, Arthrobotrys, Pseudogymnoascus, Fusarium, Nectria, Remersonia, Humicola, Trichoderma, Chaetomium, Mortierella, and Solicoccozyma were positively correlated with OM $(P<0.05)$, AK, and Salt, among which Nectria, Humicola, and Trichoderma also had significant positive correlations with AK $(P<0.001)$. Chaetomium was significantly positively correlated with the Simpson index. In bacterial genera, Ellin6067, Sphingomonas, Pseudolabrys, Gemmatimonas, and Bacillus were significantly positively correlated with TK, AK, and Salt but significantly negatively correlated with $\mathrm{pH}(P<0.05)$. Moreover, there was a significantly positive correlation between Candidatus_Udaeobacter, RB41, and Arthrobacter and pH, while a negative correlation was observed between these genera and TK, AK, and Salt $(P<0.05)$. RB41 and Arthrobacter were significantly negatively correlated with $\mathrm{AK}(P<0.001)$.

Fungal and bacterial community single factor co-correlation networks

The microbial single factor network directly showed the complex co-correlation between

Peer] reviewing PDF | (2021:07:64224:1:2:NEW 19 Nov 2021) 
327 the rhizosphere soil microbes. The top 25 dominant fungal and bacterial genera were selected

328 and used to construct the relationship network from the rhizosphere soil fungal and bacterial 329 communities. The network topology showed different sizes of networks of fungal and bacterial 330 communities (220 and 320 nodes, respectively) (Table 4). The average connectivity (the average 331 number of connections between each node and other nodes in the network) of 4.4 for fungal and 3326.4 for bacterial genera was observed. The average clustering coefficients, which describe how 333 close the neighbors of a node are, were 0.67 and 0.79 for fungi and bacteria, respectively. This 334 indicated that the bacterial network was denser and more complicated than the fungal network. 335 The average path distance in the fungal network (1.86) was slightly longer than that in the 336 bacterial network (1.57), indicating that fungi might interact with each other for a long time. In 337 the fungal network, the significantly higher abundances of Massilia and Fusarium with stronger 338 correlations with other genera were found, indicating that these two genera occupy important 339 niche in the rhizosphere soil of Fritillaria ussuriensis (Figure 8). In the bacterial network, RB41, 340 Bacillus, Arthrobacter, and Bryoacter all showed a higher correlation, indicating the close 341 interaction between soil bacteria. Compared with the bacterial network, the correlation of fungal 342 network was mostly positive, implying that most pathogenic fungi might cause disease in 343 Fritillaria ussuriensis through a synergistic effect, while it was possible that more bacteria were 344 restricted by each other.

345

346

347

348

349

350

351

352

353

354

355

356

357

358

359

\section{Discussion}

In this study, we compared the physicochemical properties of fungal and bacterial communities of the rhizosphere soil, such as the abundance, diversity, structure, composition, and interactions at different health levels of Fritillaria ussuriensis. The results showed that the resident soil microbial community plays a role in maintaining the health of Fritillaria ussuriensis. The environmental factors were related to the dynamic variation of the microbial community structure. The difference in soil microbial flora and nutrients was an important reason for the occurrence of Fritillaria wilt disease.

Many studies have shown that the microbial diversity of the rhizosphere soil was positively correlated with plant health (Yang et al., 2017). Our study also found that the diversity of the microbial community in the healthy soil sample was higher than that in diseased soil samples $(P$ and B); this research is consistent with the result of Wang et al. (2017) and Yang et al. (2017) on the microbial community diversity of tobacco wilt disease. It might because the root exudates of healthy plants could provide more nutrients for soil microorganisms, thereby increasing the species richness and diversity of the microbial community (Xuan et al., 2012). Furthermore, we 
360

361

362

363

364

365

366

367

368

369

370

371

372

373

374

375

376

377

378

379

380

381

382

383

384

385

386

387

388

389

390

391

392

393

394

found a negative relationship between the soil microbial diversity and Fritillaria wilt disease (P and B samples), which can support the idea that microbial diversity is a key factor controlling the pathogen invasion (van Elsas et al., 2012). In addition, beneficial rhizosphere soil microbes occupy space and trophic niches by competing with other counterparts and improve nutrient uptake and plant health and growth by establishing interactions with plant roots (Richardson et al., 2001). Related studies have shown that the specific changes in soil microbial community diversity and structure were related to differences in soil structure and plant types (Yin et al., 2014; Ding et al., 2019). For example, Chen et al. (2013) found that the microbial diversity of banana wilt disease soil was higher than that of healthy soil. It was because the continuous disease caused changes in the soil physicochemical properties and soil microbial community structures (Xie et al., 2004). In addition, the invasion of pathogenic microorganisms destroyed the original microbial ecological balance in rhizosphere soil, leading to an abnormal increase or decrease of certain microorganisms, the microbial diversity would temporarily increase before the new balance was established (Chi. 1999). Previous studies have shown that the greater growth of the above-ground part of herbaceous plants could provide a large amount of litter for soil microorganisms, and the root system was well-developed, dense in the surface layer of the soil, the root exudates and dead roots were rich energy materials for microorganisms (Smith et al., 1990). In this study, the mass deaths of Fritillaria ussuriensis in blank soil produced a large amount of spoilage, which also explained the slightly increased soil organic matter content and soil microbial diversity of Fritillaria ussuriensis in blank soil samples.

The PCoA analysis revealed significant variations in the microbial community structure of Fritillaria ussuriensis from the rhizosphere soil at different health levels. We found significant differences in the fungal and bacterial community structure of diseased and healthy soil samples $(\mathrm{H}, \mathrm{P}$, and $\mathrm{B})$; this is consistent with the results of previous research conducted by Song et al. (2016) on root rot disease of Fritillaria ussuriensis. The differences in the microbial community structure can be due to different plant root systems, which are consistent with the findings of many previous studies on a key role that plants play in shaping the microbial community structures in the rhizosphere of plants (Philippot et al., 2013; Edwards et al., 2015). Another reason for significant variations in the microbial community structure in soils at different health levels may be significant differences in environmental factors, as soil physicochemical properties have significant impacts on the microbial community structure (Lauber et al., 2008). For example, Wang et al. (2021) found that soil physicochemical properties were important influencing factors driving changes in the number of soil microorganisms of Gastrodia elata. Li et al. (2021) compared the differences of the physicochemical properties and microorganisms from low disease soils and high disease soils of strawberry, which found that the total nitrogen 
395

396

397

398

399

400

401

402

403

404

405

406

407

408

409

410

411

412

413

414

415

416

417

418

419

420

421

422

423

424

425

426

427

428

429

content and the spore germination rate of Fusarium oxysporum were extremely significantly negatively correlated. The above showed that environmental factors were the key factors that produce differences in the microbial community structures.

Microbial taxonomic composition strongly varied in rhizosphere soils at different health levels. Ascomycota, Mortierellomycota, and Basidiomycota are the most abundant fungal phyla. Ascomycota and Basidiomycota with high relative abundances are also two common fungal phyla in soils under continuous cropping with vanilla and peanut (Wu et al., 2017; Li et al., 2014). Related research showed that many species of Mortierellomycota can cause plant diseases, and some species of Mortierella can be isolated from stored rotten fruits (Chen. 1992). We found a significant increase in the abundance of Mortierellomycota in diseased samples (P and B), indicating that this fungal phylum might promote the occurrence of Fritillaria wilt disease. In bacterial phyla, except for Proteobacteria with the highest abundance (31.89\%), Acidobacteria, Actinobacteria, Chloroflexi, and Firmicutes were relatively abundant, among which Actinobacteria and Firmicutes are known to produce high levels of secondary metabolites and participate in the decomposition, transformation process, and carbon deposition in the rhizosphere (Palaniyandi et al., 2013; Kim et al., 2011). Previous studies found that higher abundances of Actinobacteria and Firmicutes can cause the effective inhibition of Rhizoctonia (Mendes et al., 2011), while Acidobacteria, Chloroflexi, and Bacteroidetes are mainly involved in the decomposition of organic matter (Ai et al., 2015). The results indicated that the variations in the abundance of phyla play an essential role in stimulating the pathological process of Fritillaria ussuriensis.

We made the following analysis at the genus level of soil fungi and bacteria: for fungi, Mortierella was the most abundant genus in soil samples. Previous studies have shown that some species of Mortierella can produce antibiotics, and several isolates were used to develop antagonists to plant pathogens (Tagawa et al., 2010). In contrast, there have also been reports suggesting that certain species of Mortierella can cause disease; for example, Mortierella bainieri parasitizes Agaricus bisporus, which results in rough stipe (Palaniyandi et al., 2013). In this study, the relative abundance of Mortierella in diseased soils (P and B) significantly increased, therefore, we speculated that the relative abundance of pathogenic species in Mortierella genus in rhizosphere soil of Fritillaria ussuriensis was much higher than that of beneficial species. In future research, we will isolate these species in Mortierella and determine their role in the pathological mechanism of Fritillaria ussuriensis. The relative abundances of Fusarium and Humicola in diseased soils (P and B) significantly increased. Fusarium is a wiltcausing pathogen, and Humicola is the pathogenic fungus that causes root rot in plants (Ginetti et al., 2012). The relative abundance of these two genera is an important indicator for identifying 
430

431

432

433

434

435

436

437

438

439

440

441

442

443

444

445

446

447

448

449

450

451

452

453

454

455

456

457

458

459

460

461

462

463

Fritillaria wilt disease. Among the bacteria, the relative abundance of Sphingomonas increased significantly with increasing the severity of disease $(H \rightarrow P \rightarrow B)$. Ali et al. (2019) found that Sphingomonas could promote plant growth by transforming organic matter, indicating that as the disease worsens, the relative abundance of Sphingomonas constantly increased, which resulted in antagonizing pathogen and maintaining the balance between rhizosphere soil microbes. The RB41 genus from the phylum Acidobacteria in the healthy soil had the highest relative abundance. Previous studies have shown that Acidobacteria could degrade lignin and cellulose to improve soil nutrients (Pankratov et al., 2011), indicating that the RB41 was dominant in the healthy soil of Fritillaria ussuriensis. The functions of Arthrobacter in efficiently degrading soil organic matter and alkaloids have been reported (Guo et al., 2019). The highest relative abundance of Arthrobacter in the Healthy sample indicated that Arthrobacter contributes to soil nutrient cycling. It has been confirmed that Bacillus exerts a significant antagonistic effect on pathogens (Lin et al., 2020). We found a significant increase in the relative abundance of Bacillus after infection (P and B), indicating that this genus plays a critical role in the efficient inhibition of pathogenic microbes. The studies on disease-suppressive soils have shown that the plant root system would recruit beneficial microbes after being infected by pathogens, enhance biological activity, and inhibit pathogens (Raaijmakers et al., 2009). The pathogen-resistant soil is formed as a result of the long-term effect of soil infestation (Berendsen et al., 2012), which indicates that strict regulations can be applied by accumulating some beneficial bacteria in diseased soils (P and B) of Fritillaria ussuriensis, which explains that the abundance of beneficial microbes, such as Sphingomonas and Bacillus, significantly increased with increasing

the severity of disease $(\mathrm{H} \rightarrow \mathrm{P} \rightarrow \mathrm{B})$. The highest relative abundances of $R B 41$ and Arthrobacter in Healthy soils indicated that these two bacterial genera had a great influence on maintaining the health of Fritillaria ussuriensis and ecological balance of rhizosphere soil.

Environmental factors have a significant impact on the diversity and structure of soil microbial communities (Zeng et al., 2016). Studies have shown that the plant abscissions and secretions could promote the diversity of the soil microbial community and the content of organic matter (Kuzyakov et al., 2009). In this study, the Fritillaria ussuriensis have withered in large numbers at the end of the disease, so the content of organic matter in blank soil increased significantly, and microbial diversity also increased. On the other hand, soil salt content could directly inhibit the activity of microorganisms, meanwhile, influence the structure and composition of microbial community by changing soil fertility (Yan et al., 2012). In our study, we found that the salt content of the diseased soils ( $\mathrm{P}$ and $\mathrm{B}$ ) increased significantly and the microbial diversity decreased significantly. There was a negative correlation between soil salt 
464

465

466

467

468

469

470

471

472

473

474

475

476

477

478

479

480

481

482

483

484

485

486

487

488

489

490

491

492

493

494

495

496

497

498

content and bacterial diversity, which was consistent with the research results of Liu et al. (2021) on cotton soil bacterial communities at different disease levels. Changes in soil nutrients could affect the composition of microbial communities (Feng et al., 2019), and enrichment of nutrient elements could increase the number of pathogenic microorganisms, leading to an increase in plant disease rates (Song et al., 2017). For example, Liu et al. (2020) showed that when the N content in the soil was low, the incidence of wheat root rot was significantly decreased, and it was closely related to the decrease of Fusarium. We also found that TN, AN, TP, AP, TK and AK were significantly increased in disease ( $\mathrm{P}$ and $\mathrm{B}$ ) soil through data analysis, and they were positively correlated with the abundance of pathogenic microorganisms such as Fusarium and Humicola et al. In addition, soil $\mathrm{pH}$ was an important factor that determined the diversity and structure of soil microbial communities (Bainard et al., 2016; Meng et al., 2019). Studies have shown that fungi were more common in acidic soils (Rousk et al. ., 2009), but when the pH value increased, the soil microbial diversity also increased, the bacterial growth rate increased, and the bacterial community composition changed (Baath et al., 1994), which explained the positive correlation between soil $\mathrm{pH}$ and bacterial diversity in this research. It can be seen that changes in environmental factors have caused changes in the number, diversity and structure of soil microorganisms, and the correlation between environmental factors and soil microorganisms affects the health of Fritillaria ussuriensis.

Microbial ecological networks revealed distinct patterns of the microbial community in the rhizosphere soil of Fritillaria ussuriensis. In the fungal networks, Fusarium and Humicola were dominant, yet most sequences of Fusarium were not affected by the wilt pathogenic species (Fusarium oxysporum), which can induce disease (Wu et al., 2017). High incidence of disease may be associated with an increased abundance of other congeneric species, indicating that the microbial interactions have more influence on plant health. The correlation-based bacterial network was more complicated than that of fungi. Previous studies have shown that more interactions can promote cooperation in the complex microbial community (Zhang et al., 2014). Although high levels of cooperation might be linked to a higher function of the community, such interactions can also cause destabilization (Coyte et al., 2015). Highly connected networks can stabilize the soil microbial community and improve the overall resistance to pathogens (Scheffer et al., 2012). Bahram et al. (2018) have shown that both the environmental factors and microbial correlation could affect the diversity and structure of microbial communities. Eldridge et al. (2015) have shown that the difference in the correlation between fungi and bacteria in the soil microbial ecological network was mainly determined by the degree of soil interference, and environmental factors could increase the instability of the microbial community structure. Therefore, changes in environmental factors affected the soil microbial correlation, 
499

500

501

502

503

504

505

506

507

508

509

510

511

512

513

514

515

516

517

518

519

520

521

522

523

524

525

526

527

528

529

530

531

532

environmental factors and microbial correlation complement each other, and together affected the health of plants. Based on the impact of environmental factors on microorganisms and the microbial association network, correlation-based variations of microbes in the rhizosphere soil at different health levels can be understood. This can lay a foundation for the systematic study on the interaction between microbial genera in the pathological process of Fritillaria ussuriensis.

This research systematically explained the physicochemical properties, the diversity and structure of microbial communities, the correlation between environmental factors and soil microorganisms, and the co-correlation network among microorganisms in the rhizosphere soil of Fritillaria ussuriensis at different health levels. However, there were some limitations in our study. First of all, as an endemic species in Northeast China, Fritillaria ussuriensis had certain limitations in the planting range and growth environment. In addition, this study did not involve research on the effects of Fritillaria ussuriensis root exudates in different health levels on soil physicochemical properties and soil microbial communities. Through high-throughput sequencing, the dominant populations of soil microorganisms in different health levels were determined, but they were not isolated, and pathological studies were not systematically carried out. In future research, we will make up for these shortcomings, isolate and cultivate these beneficial microorganisms in Fritillaria ussuriensis rhizosphere soil for disease resistance research. The above work will be of great significance to the prevention of Fritillaria ussuriensis wilt disease and the maintenance of a healthy soil micro-ecosystem.

Conclusion

The physicochemical properties and microbial community diversity of Fritillaria ussuriensis rhizosphere soils in different health levels were significantly different. Compared with the healthy soil, the diversity of diseased soils (P and B) showed a decreasing trend. There were also significant differences in the composition of microbial communities in rhizosphere soils of Fritillaria ussuriensis at different health levels. The relative abundance of Fusarium and Humicola in diseased soils (P and B) was significantly increased, while in healthy soils, the relative abundance of $R B 41$ and Arthrobacter was the highest. These soil microorganisms affect the health level of Fritillaria ussuriensis through a close and complex relationship network. At the same time, this research revealed that the differences in microbial communities from the rhizosphere soils of Fritillaria ussuriensis were the key factors that caused changes in environmental factors. In future research, we will isolate beneficial microorganisms from healthy rhizosphere soil samples and research the mechanism of the beneficial microorganisms growth promotion and disease resistance in Fritillaria ussuriensis. In addition, dominant fungi Mortierella in present research needs further research to determine the role of key species in the 
533

534

535

536

537

538

539

540

541

542

543

544

545

546

547

548

549

550

551

552

553

554

555

556

557

558

559

560

561

562

pathological mechanism of Fritillaria ussuriensis. These work will provide an important basis for the rhizosphere soil micro-ecology restoration and wilt disease prevention of Fritillaria ussuriensis.

Acknowledgements

This research was funded by [National Key Research and Development Program] grant number (2016YFC0500308-08), [National Natural Science Foundation of China] grant number (31670649, 31700564, 31170597, 31200484).

References

Ai C, Liang GQ, Sun JW, Wang XB, He P, Zhou W, He XH. 2015. Reduced dependence of rhizosphere microbiome on plant-derived carbon in 32-year long-term inorganic and organic fertilized soils. Soil Biology and Biochemistry, 80:70-78 DOI 10.1016/j.soilbio.2014.09.028.

Ali A, Mohanta TK, Asaf S, Rehman N, Al-Housni S, Al-Harrasi A, Khan AL, Al-Rawahi A. 2019. Biotransformation of benzoin by Sphingomonas sp. LK11 and ameliorative effects on growth of Cucumis sativus. Archives of Microbiology, 201(5):591-601 DOI 10.1007/s00203019-01623-1.

Baath E, Arnebrant K. 1994. Growth rate and response of bacterial communities to $\mathrm{pH}$ in limed and ash treated forest soils. Soil Biology and Biochemistry, 26(8):995-1001 DOI 10.1016/00380717(94)90114-7.

Baayen RP, O’Donnell K, Breeuwsma S, Geiser DM, Waalwijk C. 2001. Molecular relationships of fungi within the Fusarium redolens-F. hostae Clade. Phytopathology, 91(11):1037-1044 DOI 10.1094/phyto.2001.91.11.1037.

Bahram M, Hildebrand F, Forslund SK, Anderson JL, Soudzilovskaia NA, Bodegom PM, Bengtsson-Palme J, Anslan S,Coelho LP, Harend H, Huerta-Cepas J, Medema MH, Maltz MR, Mundra S, Olsson PA, Pent M, Polme S, Sunagawa S, Ryberg M, Tedersoo L, Bork P. 2018. Structure and function of the global topsoil microbiome. Nature, 560(7717):233-237 DOI 10.1038/s41586-018-0386-6.

Bainard LD, Hamel C, Gan Y. 2016. Edaphic properties override the influence of crops on the composition of the soil bacterial community in a semiarid agroecosystem. Applied Soil Ecology, 105:160-168 DOI 10.1016/j.apsoil.2016.03.013.

Bao SD. Agrochemical soil analysis. 2000. Agricultural Press of China: Beijing, China, PP:25- 
109.

564 Benizri E, Piutti S, Verger S, Pagès L, Vercambre G, Poessel JL, Michelot P. 2005. Replant 565 diseases: Bacterial community structure and diversity in peach rhizosphere as determined by 566 metabolic and genetic fingerprinting. Soil Biology and Biochemistry, 37(9):1738-1746 DOI 567 10.1016/j.soilbio.2005.02.009.

568 Berendsen RL, Pieterse CMJ, Bakker PAHM. 2012. The rhizosphere microbiome and plant 569 health. Trends in Plant Science, 17(8):478-486 DOI 10.1016/j.tplants.2012.04.001.

570 Buée M, Reich M, Murat C, Morin E, Nilsson RH, Uroz S, Martin F. 2009. 454 Pyrosequencing 571 analyses of forest soils reveal an unexpectedly high fungal diversity. New Phytologist, 572 184(2):449-456 DOI 10.1111/j.1469-8137.2009.03003.x.

573 Bulluck III LR, Brosius M, Evanylo GK, Ristaino JB. 2002. Organic and synthetic fertility 574 amendments influence soil microbial, physical and chemical properties on organic and 575 conventional farms. Applied Soil Ecology, 19(2):147-160 DOI 10.1016/s0929-1393(01)00187-1.

576 Caporaso JG, Kuczynski J, Stombaugh J, Bittinger K, Bushman FD, Costello EK, Fierer N, Peña 577 AG, Goodrich JK, Gordon JI, Huttley GA, Kelley ST, Knights D, Koenig JE, Ley RE, Lozupone 578 CA, McDonald D, Muegge BD, Pirrung M, Reeder J, Sevinsky JR, Turnbaugh PJ, Walters WA, 579 Widmann J, Yatsunenko T, Zaneveld J, Knight R. 2010. QIIME allows analysis of high580 throughput community sequencing data. Nature Methods, 7(5):335-336 DOI 581 10.1038/nmeth.f.303.

582 Chen Y, Jiang Y, Huang H, Mou L, Ru J, Zhao J, Xiao S. 2018. Long-term and high583 concentration heavy-metal contamination strongly influences the microbiome and functional 584 genes in Yellow River sediments. Science of the Total Environment, 637-638:1400-1412 DOI 585 10.1016/j.scitotenv.2018.05.109.

586 Chen B, Huang X, Liu XY, Zhou DB, Tan X, Gao ZF, Zhang XY, Qi CL.2013. Diversity of soil 587 bacterial community in banana orchards infected with wilt disease. Chinese Journal of Applied 588 Ecology, 24(8):2281-2286 DOI 10.13287/j.1001-9332.2013.0387.

589 Chen FJ .1992. Mortierella species in China. Mycosystema, 5:23-64.

590 Chi ZM. 1999, Microbial Ecology, Shandong University Press: Ji’nan China, PP:172-178.

591 Collignon C, Uroz S, Turpault MP, Frey-Klett P. 2011. Seasons differently impact the structure 
592 of mineral weathering bacterial communities in beech and spruce stands. Soil Biology and 593 Biochemistry, 43(10):2012-2022 DOI 10.1016/j.soilbio.2011.05.008.

594 Coyte KZ, Schluter J, Foster KR. 2015. The ecology of the microbiome: Networks, competition, 595 and stability. Science, 350(6261):663-666 DOI 10.1126/science.aad2602.

596 Daguerre Y, Siegel K, Edel-Hermann V, Steinberg C. 2014. Fungal proteins and genes 597 associated with biocontrol mechanisms of soil-borne pathogens: a review. Fungal Biology 598 Reviews, 28(4): 97-125 DOI 10.1016/j.fbr.2014.11.001.

599 Day PD, Berger M, Hill L, Fay MF, Leitch AR, Leitch IJ, Kelly LJ. 2014. Evolutionary 600 relationships in the medicinally important genus Fritillaria L. (Liliaceae). Molecular 601 Phylogenetics and Evolution, 80:11-19 DOI 10.1016/j.ympev.2014.07.024.

602 Ding CH, Guo SL, Sun HF, Ma WW, Zhou B, Wang ZY. 2018. Research progress of medicinal 603 plant Fritillaria ussuriensis Maxim. Guiding Journal of Traditional Chinese Medicine and 604 Pharmacy, 24(03): 73-75+78 DOI CNKI:SUN:HNZB.0.2018-03-024.

605 Ding LJ, Cui HL, Nie SA, Long XE, Duan GL, Zhu YG. 2019. Microbiomes inhabiting rice 606 roots and rhizosphere. FEMS Microbiology Ecology, 95(5):1-13 DOI 10.1093/femsec/fiz040.

607 Doi R, Ranamukhaarachchi SL. 2009. Correlations between soil microbial and physicochemical 608 variations in a rice paddy: implications for assessing soil health. Journal of Biosciences, 609 34(6):969-976 DOI 10.1007/s12038-009-0111-6.

610 Doran JW, Sarrantonio M, Liebig MA. 1996. Soil health and sustainability. Advances in 611 Agronomy, 56(08):1-54 DOI 10.1016/S0065-2113(08)60178-9.

612 Duffy BK, Ownley BH, Weller DM. 1997. Soil chemical and physical properties associated with 613 suppression of take-all of wheat by Trichoderma koningii. Phytopathology, 87(11):1118-1124 614 DOI 10.1094/phyto.1997.87.11.1118.

615 Edgar RC. 2013. UPARSE: highly accurate OTU sequences from microbial amplicon reads. 616 Nature Methods, 10(10):996-998 DOI 10.1038/nmeth.2604.

617 Edwards J, Johnson C, Santos-Medellín C, Lurie E, Podishetty NK, Bhatnagar S, Eisenc JA, 618 Sundaresan V. 2015. Structure, variation, and assembly of the root-associated microbiomes of 619 rice. Proceedings of the National Academy of Sciences, 112(8): E911-E920 DOI $620 \quad 10.1073 /$ pnas.1414592112.

621 Eldridge DJ, Woodhouse JN, Curlevski NJA, Hayward M, Brown MV, Neilan BA. 2015. Soil- 
622 foraging animals alter the composition and co-occurrence of microbial communities in a desert 623 shrubland. The ISME Journal, 9(12):2671-2681 DOI 10.1038/ismej.2015.70.

624 Feng YX, Hu YY, Wu JS, Chen JH, Yrjälä K, Yu WW. 2019. Change in microbial communities, 625 soil enzyme and metabolic activity in a Torreya grandis plantation in response to root rot disease. 626 Forest Ecology and Management, 432:932-941 DOI 10.1016/j.foreco.2018.10.028.

627 Fierer N, Leff JW, Adams BJ, Nielsen UN, Bates ST, Lauber CL, Owense S, Gilberte JA, Wallh 628 DH, Caporasoe JG. 2012. Cross-biome metagenomic analyses of soil microbial communities and 629 their functional attributes. Proceedings of the National Academy of Sciences, 109(52): 2139063021395 DOI 10.1073/pnas.1215210110

631 Fu YJ, Zhang JL, Hou XQ. 2019. Comparative analysis of fungi diversity in rizospheric and non632 rhizospheric soil from Cypripedium macranthum estimated via high-throughput sequencing. 633 Acta Agriculturae Boreali-occidentalis Sinica, 28(02):1-7 DOI 10.7606/j.issn.1004$634 \quad 1389.2019 .02 .013$.

635 Ginetti B, Uccello A, Bracalini M, Ragazzi A, Jung T, Moricca S. 2012. Root rot and dieback of 636 Pinus pinea caused by phytophthora Humicola in Tuscany, central Italy. Plant Disease, 637 96(11):1694 DOI 10.1094/PDIS-05-12-0451-PDN

638 Gong MF, He JZ, Sun XT, Zhang LL. 2007. Research on the relationship between soil microbes 639 and soil disease suppression. Xinjiang Agricultural Sciences, 044(006):814-819 DOI $640 \quad 10.3969 /$ j.issn.1001-4330.2007.06.019.

641 Guo XH, Xie CY, Wang LJ, Li QF, Wang Y. 2019. Biodegradation of persistent environmental 642 pollutants by Arthrobacter sp. Environmental Science and Pollution Research, DOI $64310.1007 / \mathrm{s} 11356-019-04358-0$

644 Halifu S, Deng X, Song XS, An YN, Song RQ. 2019. Effects of sphaeropsis blight on 645 rhizosphere soil bacterial community structure and soil rhysicochemical properties of Pinus 646 sylvestris var. mongolica in Zhanggutai, China. Forests, 10(11):954 DOI 10.3390/f10110954.

647 Karlen DL, Mausbach MJ, Doran JW, Cline RG, Harris RF, Schuman GE. 1997. Soil quality: a 648 concept, definition, and framework for evaluation (a guest editorial). Soil Science Society of 649 America Journal, 61(1):4-10 DOI 10.2136/sssaj1997.03615995006100010001x.

650 Kim YC, Leveau J, McSpadden Gardener BB, Pierson EA, Pierson LS, Ryu CM. 2011. The 651 multifactorial basis for plant health promotion by plant-associated bacteria. Applied and 652 Environmental Microbiology, 77(5):1548-1555 DOI 10.1128/aem.01867-10. 
653 Klarner H, Streck A, Siebert H. 2016. PyBoolNet: a python package for the generation, analysis 654 and visualization of boolean networks. Bioinformatics, 33(5):770-772 DOI 655 10.1093/bioinformatics/btw682.

656 Kloepper JW, Beauchamp CJ. 1992. A review of issues related to measuring colonization of 657 plant roots by bacteria. Canadian Journal of Microbiology, 38(12):1219-1232 DOI $658 \quad 10.1139 / \mathrm{m} 92-202$.

659 Kõljalg U, Nilsson RH, Abarenkov K, Tedersoo L, Taylor AFS, Bahram M, Bates ST, Bruns TD, 660 Bengtsson-Palme J, Callaghan TM, Douglas B, Drenkhan T, Eberhardt U, Dueñas M, Grebenc T, 661 Griffith GW, Hartmann M, Kirk PM, Kohout P, Larsson E, Lindahl BD, Lücking R, Martin MP, 662 Matheny PB, Nguyen NH, Niskanen T, Oja J, Peay KG, Peintner U, Peterson M, Pöldmaa K, 663 Saag L, Saar I, Schüßler A, Scot JA, Senés C, Smith ME, Suja A, Taylor DL, Telleria MT, Weiß 664 M, Larsson KH. 2013. Towards a unified paradigm for sequence-based identification of fungi. 665 Molecular Ecology, 22(21):5271-5277 DOI 10.1111/mec.12481.

666 Kuzyakov Y, Blagodatskaya E, Blagodatsky S. 2009. Comments on the paper by Kemmitt et al. 667 (2008) "Mineralization of native soil organic matter is not regulated by the size, activity or 668 composition of the soil microbial biomass - A new perspective" [Soil Biology \& Biochemistry 669 40, 61-73]: The biology of the Regulatory Gate. Soil Biology and Biochemistry, 41(2):435-439 670 DOI 10.1016/j.soilbio.2008.07.023.

671 Lauber CL, Strickland MS, Bradford MA, Fierer N. 2008. The influence of soil properties on the 672 structure of bacterial and fungal communities across land-use types. Soil Biology and 673 Biochemistry, 40(9):2407-2415 DOI 10.1016/j.soilbio.2008.05.021.

674 Li FL, Liu M, Li ZP, Jiang CY, Han FX, Che YP. 2013. Changes in soil microbial biomass and 675 functional diversity with a nitrogen gradient in soil columns. Applied Soil Ecology, 64:1-6 DOI 676 10.1016/j.apsoil.2012.10.006.

677 Li MY, Chen SS, Wang SM. 2021. Contrast of physicochemical properties and biological 678 characteristics of low disease and high disease soils of continuous cropping strawberry. Jiangsu 679 Journal of Agricultural Sciences, 37(04):910-918 DOI CNKI:SUN:JSNB.0.2021-04-014.

680 Li XG, Ding CF, Zhang TL, Wang XX. 2014. Fungal pathogen accumulation at the expense of 681 plant-beneficial fungi as a consequence of consecutive peanut monoculturing. Soil Biology and 682 Biochemistry, 72:11-18 DOI 10.1016/j.soilbio.2014.01.019. 
684 efficiency of biocontrol strain YB-161 against wheat crown rot. Journal of Plant Protection, 685 47(04):939-948 DOI 10.13802/j.cnki.zwbhxb.2020.2019173.

686 Liu DH, Zhang XJ, Wang P, Hu C, QiaoY, Zhang Z, Li SL. 2020. Effects of different 687 fertilization treatments on wheat root rot and the diversity of fungi in rhizosphere soil. Hubei 688 Agricultural Sciences, 59(21):30-34+50 DOI 10.14088/j.cnki.issn0439-8114.2020.21.007.

689 Liu HY, Zhang RF, Wang W, Yang HL, Yao J. 2021. Characteristics of soil bacterial community 690 structure in cotton fields with different incidence of Verticillium wilt in Xinjiang. Ecology and 691 Environmental Sciences, 30(01):72-80 DOI 10.16258/j.cnki.1674-5906.2021.01.009.

692 Lozupone C, Hamady M, Knight R. 2006. UniFrac-An online tool for comparing microbial 693 community diversity in a phylogenetic context. BMC Bioinformatics, 7(1):371 DOI 694 10.1186/1471-2105-7-371.

695

696

697

698

699

700

701

702

703

704

705

706

707

708

709

710

712

713

711 Palaniyandi SA, Yang SH, Zhang L, Suh JW. 2013. Effects of Actinobacteria on plant disease

Magoc T, Salzberg SL. 2011. FLASH: fast length adjustment of short reads to improve genome assemblies. Bioinformatics, 27(21):2957-2963 DOI 10.1093/bioinformatics/btr507.

Meirmans PG. 2006. Using the AMOVA framework to estimate a standardized genetic differentiation measure. Evolution, 60(11):2399-2402 DOI 10.1111/j.00143820.2006.tb01874.x.

Mendes R, Kruijt M, de Bruijn I, Dekkers E, van der Voort M, Schneider JHM, Piceno YM, DeSantis TZ, Andersen GL, Bakker PAHM, Raaijmakers JM. 2011. Deciphering the rhizosphere microbiome for disease-suppressive bacteria. Science, 332(6033):1097-1100 DOI 10.1126/science.1203980.

Meng MJ, Lin J, Guo XP, Liu X, Wu JS, Zhao YP, Zhang JC. (2019). Impacts of forest conversion on soil bacterial community composition and diversity in subtropical forests. Catena, 175:167-173 DOI 10.1016/j.catena.2018.12.017.

Mori H, Maruyama F, Kato H, Toyoda A, Dozono A., Ohtsubo Y, Nagata Y, Fujiyama A, Tsuda M, Kurokawa K. 2013. Design and experimental application of a novel non-degenerate universal primer set that amplifies prokaryotic 16S rRNA genes with a low possibility to amplify eukaryotic rRNA genes. DNA Research, 21(2):217-227 DOI 10.1093/dnares/dst052. suppression and growth promotion. Applied Microbiology and Biotechnology, 97(22):96219636 DOI 10.1007/s00253-013-5206-1 
714 Pankratov TA, Ivanova AO, Dedysh SN, Liesack W. 2011. Bacterial populations and 715 environmental factors controlling cellulose degradation in an acidic Sphagnum peat. 716 Environmental Microbiology, 13(7):1800-1814 DOI 10.1111/j.1462-2920.2011.02491.x.

717 Park I, Kim WJ, Yeo SM, Choi G, Kang YM, Piao R, Moon BC. 2017. The complete chloroplast 718 genome sequences of Fritillaria ussuriensis Maxim. and Fritillaria cirrhosa D. Don, and 719 comparative analysis with other Fritillaria species. Molecules, 22(6):982 DOI $720 \quad 10.3390 /$ molecules22060982.

721 Peiffer JA, Spor A, Koren O, Jin Z, Tringe SG, Dangl JL, Bucklera ES, Ley RE. 2013. Diversity 722 and heritability of the maize rhizosphere microbiome under field conditions. Proceedings of the 723 National Academy of Sciences, 110(16):6548-6553 DOI 10.1073/pnas.1302837110.

724 Pérez-Piqueres A, Edel-Hermann V, Alabouvette C, Steinberg C. 2006. Response of soil 725 microbial communities to compost amendments. Soil Biology and Biochemistry, 38(3):460-470 726 DOI 10.1016/j.soilbio.2005.05.025.

727 Philippot L, Raaijmakers JM, Lemanceau P, van der Putten WH. 2013. Going back to the roots: 728 the microbial ecology of the rhizosphere. Nature Reviews Microbiology, 11(11):789-799 DOI $72910.1038 /$ nrmicro3109.

730 Raaijmakers JM, Paulitz TC, Steinberg C, Alabouvette C, Moënne-Loccoz Y. 2009. The 731 rhizosphere: a playground and battlefield for soilborne pathogens and beneficial microorganisms. 732 Plant Soil, 321(1-2):341-361 DOI 10.1007/s11104-008-9568-6.

733 Richardson AE. 2001. Prospects for using soil microorganisms to improve the acquisition of 734 phosphorus by plants. Functional Plant Biology, 28(9):897-906 DOI 10.1071/pp01093.

735

Rimé D, Nazaret S, Gourbière F, Cadet P, Moënne-Loccoz Y. 2003. Comparison of sandy soils suppressive or conducive to ectoparasitic nematode damage on sugarcane. Phytopathology, 93(11):1437-1444 DOI 10.1094/phyto.2003.93.11.1437.

Rousk J, Brookes PC, Baath E. 2009. Contrasting soil pH effects on fungal and bacterial growth suggest functional redundancy in carbon mineralization. Applied and Environmental Microbiology, 75(6):1589-1596 DOI 10.1128/aem.02775-08.

Scheffer M, Carpenter SR, Lenton TM, Bascompte J, Brock W, Dakos V, van de Koppel J, van de Leemput IA, Levin SA, van Nes EH, Pascual M, Vandermeer J. 2012. Anticipating critical transitions. Science, 338(6105):344-348 DOI 10.1126/science.1225244. 
744 Schloss PD, Gevers D, Westcott SL. 2011. Reducing the effects of PCR amplification and 745 sequencing artifacts on 16S rRNA-based studies. PLoS ONE, 6(12):e27310 DOI 746 10.1371/journal.pone.0027310.

747 Sessitsch A, Weilharter A, Gerzabek MH, Kirchmann H, Kandeler E. 2001. Microbial 748 population structures in soil particle size fractions of a long-term fertilizer field experiment. 749 Applied and Environmental Microbiology, 67(9):4215-4224 DOI 10.1128/aem.67.9.4215$750 \quad 4224.2001$.

751 Shanmugam V, Verma R, Rajkumar S, Naruka DS. 2011. Bacterial diversity and soil enzyme 752 activity in diseased and disease free apple rhizosphere soils. Annals of Microbiology, 61(4):765753772 DOI 10.1007/s13213-010-0193-2.

754 Shiomi Y, Nishiyama M, Onizuka T, Marumoto T. 1999. Comparison of bacterial community 755 structures in the rhizoplane of tomato plants grown in soils suppressive and conducive towards 756 bacterial wilt. Applied and Environmental Microbiology, 65(9):3996-4001 DOI 757 10.1128/aem.65.9.3996-4001.1999.

758 Smith JL, Paul E A. 1990. The significance of soil microbial biomass estimations. In: Bollag JM, 759 Stotzky G. Soil Biochemistry. New York: Marcel Dekker Inc, PP:359-396.

760 Song XH, Wang Y, Li LY, TanY. 2017. Research on bacteria microecology in root rot 761 rhizosphere soil of Coptis chinensis produced in Shizhu city. China Journal of Chinese Materia 762 Medica, 42(07):1304-1311 DOI 10.19540/j.cnki.cjcmm.20170222.012.

763 Song XS, Yu WJ, Zhou Q, Deng X. 2016. Microbial ecological study about the black rot of 764 Fritillaria ussuriensis and its biological control bacteria screening. Forestry Science and 765 Technology, 041(006):18-20 DOI CNKI:SUN:LYKJ.0.2016-06-006.

766 Tagawa M, Tamaki H, Manome A, Koyama O, Kamagata Y. 2010. Isolation and 767 characterization of antagonistic fungi against potato scab pathogens from potato field soils. 768 FEMS Microbiology Letters, 305(2):136-142 DOI 10.1111/j.1574-6968.2010.01928.x

769 Tenuta M, Lazarovits G. 2004. Soil properties associated with the variable effectiveness of meat 770 and bone meal to kill microsclerotia of Verticillium dahliae. Applied Soil Ecology, 25(3):219771236 DOI 10.1016/j.apsoil.2003.09.007.

772 Uroz S, Oger P, Tisserand E, Cébron A, Turpault MP, Buée M, Boer WD, Leveau JHJ, Frey773 Klett P. 2016. Specific impacts of beech and norway spruce on the structure and diversity of the 774 rhizosphere and soil microbial communities. Scientific Reports, 6(1) DOI 10.1038/srep27756. 
775 van Elsas JD, Chiurazzi M, Mallon CA, Elhottova D, Kristufek V, Salles JF. 2012. Microbial 776 diversity determines the invasion of soil by a bacterial pathogen. Proceedings of the National 777 Academy of Sciences, 109(4):1159-1164 DOI 10.1073/pnas.1109326109

778 Wang P, Chen B, Zhang H. 2017. High throughput sequencing analysis of bacterial communities 779 in soils of a typical Poyang Lake wetland. Acta Ecologica Sinica, 37(5):1650-1658 DOI $780 \quad 10.5846 /$ stxb201510052000.

781 Wang P, Meng GY, Mao RZ, Yang K, Su ZH, Wang ZQ, Yang SQ, Huang HP, He XH. 2021. 782 Soil physical and chemical properties, microorganisms and metabolites in different culture 783 environments of Gastrodia elata. Chinese Journal of Experimental Traditional Medical Formulae, 784 27(14):164-174 DOI 10.13422/j.cnki.syfjx.20210915.

785

Wang Q, Garrity GM, Tiedje JM, Cole JR. 2007. Naive bayesian classifier for rapid assignment of rRNA sequences into the new bacterial taxonomy. Applied and Environmental Microbiology, 73(16):5261-5267 DOI 10.1128/aem.00062-07.

Wang R, Zhang HC, Sun LG, Qi GF, Chen S, Zhao XY. 2017. Microbial community composition is related to soil biological and chemical properties and bacterial wilt outbreak. Scientific Reports, 7(1):343 DOI 10.1038/s41598-017-00472-6.

Wu X, Li R, Ren Y, Liu C, Zhao QY, Wu HS, Jousset A, Shen QR. 2017. Distinct roles for soil fungal and bacterial communities associated with the suppression of vanilla Fusarium wilt disease. Soil Biology and Biochemistry, 107:198-207 DIO 10.1016/j.soilbio.2017.01.010.

Xie LL, Chen QB, Wang ZH, Liu XX. 2004. A review of effects of environmental changes on soil microbe. Chinese Journal of Tropical Agriculture, 24 (3):39-47 DOI 10.3969/j.issn.10092196.2004.03.010.

Xu N, Tan GC, Wang HY, Gai XP. 2016. Effect of biochar additions to soil on nitrogen leaching, microbial biomass and bacterial community structure. European Journal of Soil Biology, 74:1-8 DOI 10.1016/j.ejsobi.2016.02.004.

$\mathrm{Xu}$ RF, Lu HN, LI XL, Chen CL. 2004. The influence of soil micro-organism to cotton Verticillium Wilt. Cotton Science, 16(006):357-359 DOI 10.3969/j.issn.1002-7807.2004.06.008.

Xu SC, Sun YK, Wang DS. 2009. Research on the relationship of soil nutrients, microorganisms and ginger skin rot disease. Journal of Changjiang Vegetables, 11:43-44 DOI 10.3865/j.issn.1001-3547.2009.11.027. 
805 Xu ZQ, Wang Z, Zhang HJ, Yang HS. 2013, Research progress in endangered medicinal plant

806 Fritillaria ussuriensis. Chinese Wild Plant Resources, 32(04):10-12+40 DOI 807 10.3969/j.issn.1006-9690.2013.04.003.

808 Xuan DT, Guong VT, Rosling A, Alström S, Chai B, Högberg N. 2011. Different crop rotation 809 systems as drivers of change in soil bacterial community structure and yield of rice, Oryza sativa. 810 Biology and Fertility of Soils, 48(2):217-225 DOI 10.1007/s00374-011-0618-5.

811 Yan F, McBratney AB, Copeland L. 2000. Functional substrate biodiversity of cultivated and 812 uncultivated a horizons of vertisols in NW New South Wales. Geoderma, 96(4):321-343 DOI 813 10.1016/s0016-7061(00)00018-5.

814 Yan N, Marschner P. 2012. Response of microbial activity and biomass to increasing salinity 815 depends on the final salinity, not the original salinity. Soil Biology and Biochemistry, 53:50-55 816 DOI 10.1016/j.soilbio.2012.04.028.

817 Yang CH, Crowley DE, Menge JA. 2001. 16S rDNA fingerprinting of rhizosphere bacterial 818 communities associated with healthy and Phytophthora infected avocado roots. FEMS 819 Microbiology Ecology, 35(2): 129-136 DOI 10.1016/s0168-6496(00)00120-3.

820 Yang HW, Li J, Xiao YH, Gu YB, Liu HW, Liang YL, Liu XD, Hu J, Meng D L, Yin HQ. 821 2017. An integrated insight into the relationship between soil microbial community and tobacco 822 bacterial wilt disease. Frontiers in Microbiology, 8:2179 DOI 10.3389/fmicb.2017.02179.

823 Yang LB, Sui X, Zhu DG, Cui FX, Li BJ, Song RQ, Ni HW. 2017. Study on fungal communities 824 characteristics of different Larix gmelini forest types in cold temperate zone. Journal of Central 825 South University of Forestry and Technology, 37(12): 76-84 DOI 10.14067/j.cnki.1673$826923 x .2017 .12 .013$.

827 Yin R, Deng H, Wang HL, Zhang B. 2014. Vegetation type affects soil enzyme activities and 828 microbial functional diversity following re-vegetation of a severely eroded red soil in sub829 tropical China. Catena, 115:96-103 DOI 10.1016/j.catena.2013.11.015.

830 Zeng QC, Dong YH, An SS. 2016. Bacterial community responses to soils along a latitudinal 831 and vegetation gradient on the Loess Plateau, China. PLOS ONE, 11(4):e0152894 DOI $83210.1371 /$ journal.pone.0152894.

833 Zhang Y, Zhao ZH, Dai MH, Jiao NZ, Herndl GJ. 2014. Drivers shaping the diversity and 834 biogeography of total and active bacterial communities in the South China Sea. Molecular 835 Ecology, 23(9):2260-2274 DOI 10.1111/mec.12739. 
836 Zhao Y, Fang X, Tian DL. 2007. Relation between the quantity of soil microbe and soil factor in 837 the second rotation Chinese fir plantation. Scientia Silvae Sinicae, 43(06):7-12 DOI 838 10.3321/j.issn:1001-7488.2007.06.002.

839 Zhou JZ, Deng Y, Shen L, Wen CQ, Yan QY, Ning D, Qin YJ, Xue K, Wu LY, He ZL, 840 Voordeckers JW, Nostrand JDV, Buzzard V, Michaletz ST, Enquist BJ, Weiser MD, Kaspari M, 841 Waide R, Yang YF, Brown JH. 2016. Temperature mediates continental-scale diversity of 842 microbes in forest soils. Nature Communications, 7: 12083 DOI 10.1038/ncomms12083.

843 Zhou YJ, Li JH, Friedman CR, Wang HF. 2017. Variation of soil bacterial communities in a 844 chronosequence of rubber tree (Hevea brasiliensis) plantations. Frontiers in Plant Science, 845 8:849 DOI 10.3389/fpls.2017.00849.

846 


\section{Table $\mathbf{1}$ (on next page)}

Comparative analysis of soil physicochemical properties of Healthy, Pathology and Blank.

Different letters indicate a significant difference at $P<0.05$ according to Duncan's new multiple range test. OM: organic matter, TN: total nitrogen, AN: available nitrogen, TP: total phosphorus, AP: available phosphorus, TK: total potassium, AK: available potassium, salt: total soluble salt. 


\begin{tabular}{|c|c|c|c|c|c|c|c|c|c|}
\hline Sample & pH & $\begin{array}{l}\text { OM } \\
\mathrm{g} / \mathrm{kg}\end{array}$ & $\begin{array}{c}\text { TN } \\
\mathrm{g} / \mathrm{kg}\end{array}$ & $\begin{array}{c}\mathrm{AN} \\
\mathrm{mg} / \mathrm{kg}\end{array}$ & $\begin{array}{c}\text { TP } \\
\mathrm{g} / \mathrm{kg}\end{array}$ & $\begin{array}{c}\mathrm{AP} \\
\mathrm{mg} / \mathrm{kg}\end{array}$ & $\begin{array}{c}\text { TK } \\
\text { g/kg }\end{array}$ & $\begin{array}{c}\text { AK } \\
\mathrm{mg} / \mathrm{kg}\end{array}$ & $\begin{array}{l}\text { salt } \\
\text { g/kg }\end{array}$ \\
\hline Healthy & $7.33 \pm 0.32 \mathrm{~A}$ & $22.33 \pm 1.03 \mathrm{~B}$ & $5.64 \pm 0.88 \mathrm{C}$ & $18.13 \pm 0.47 \mathrm{~B}$ & $2.04 \pm 0.16 \mathrm{~B}$ & $76.25 \pm 1.42 \mathrm{~B}$ & $7.03 \pm 0.29 \mathrm{~B}$ & $204.12 \pm 11.42 \mathrm{C}$ & $0.83 \pm 0.03 \mathrm{C}$ \\
\hline Pathology & $6.24 \pm 0.95 \mathrm{~B}$ & $21.26 \pm 0.99 \mathrm{~B}$ & $7.31 \pm 0.05 \mathrm{~A}$ & $21.26 \pm 1.00 \mathrm{~A}$ & $3.01 \pm 0.42 \mathrm{~A}$ & $95.52 \pm 5.14 \mathrm{~A}$ & $7.38 \pm 0.32 \mathrm{~B}$ & $230.49 \pm 18.03 \mathrm{~B}$ & $1.08 \pm 0.06 \mathrm{~B}$ \\
\hline Blank & $6.31 \pm 0.31 \mathrm{~B}$ & $26.17 \pm 0.70 \mathrm{~A}$ & $6.46 \pm 0.48 \mathrm{~B}$ & $20.47 \pm 0.66 \mathrm{~A}$ & $2.11 \pm 0.55 \mathrm{~B}$ & $80.39 \pm 0.70 \mathrm{~B}$ & $8.70 \pm 1.10 \mathrm{~A}$ & $310.22 \pm 5.00 \mathrm{~A}$ & $1.41 \pm 0.12 \mathrm{~A}$ \\
\hline
\end{tabular}




\section{Table 2 (on next page)}

Soil $\alpha$ diversity index of fungal and bacterial communities in Healthy, Pathology and Blank.

Different letters indicate significant difference at $P<0.05$ according to Duncan's new multiple range test. 


\begin{tabular}{ccccccc}
\hline & Sample & Shannon & Simpson & Ace & Chao & Coverage \\
\hline \multirow{2}{*}{ Fungi } & Healthy & $4.49 \pm 0.09 \mathrm{~A}$ & $0.031 \pm 0.00 \mathrm{~B}$ & $796.81 \pm 68.43 \mathrm{~A}$ & $802.3 \pm 70.75 \mathrm{~A}$ & $99.84 \pm 0.00 \% \mathrm{~A}$ \\
& Pathology & $4.07 \pm 0.07 \mathrm{~B}$ & $0.051 \pm 0.00 \mathrm{~A}$ & $750.59 \pm 61.03 \mathrm{AB}$ & $751.89 \pm 61.34 \mathrm{AB}$ & $99.73 \pm 0.00 \% \mathrm{~A}$ \\
& Blank & $4.27 \pm 0.14 \mathrm{~B}$ & $0.044 \pm 0.00 \mathrm{~A}$ & $806.59 \pm 65.60 \mathrm{~A}$ & $815.22 \pm 66.59 \mathrm{~A}$ & $99.84 \pm 0.00 \% \mathrm{~A}$ \\
\hline \multirow{2}{*}{ Bacteria } & Healthy & $6.59 \pm 0.06 \mathrm{a}$ & $0.0039 \pm 0.00 \mathrm{a}$ & $3057.47 \pm 61.69 \mathrm{a}$ & $3044.13 \pm 63.73 \mathrm{a}$ & $98.13 \pm 0.00 \% \mathrm{a}$ \\
& Pathology & $6.46 \pm 0.01 \mathrm{~b}$ & $0.0037 \pm 0.00 \mathrm{a}$ & $2943.83 \pm 72.98 \mathrm{ab}$ & $2895.71 \pm 86.24 \mathrm{~b}$ & $97.86 \pm 0.00 \% \mathrm{a}$ \\
& Blank & $6.54 \pm 0.03 \mathrm{ab}$ & $0.0038 \pm 0.00 \mathrm{a}$ & $3029.25 \pm 19.63 \mathrm{a}$ & $2992.48 \pm 6.61 \mathrm{ab}$ & $97.94 \pm 0.00 \% \mathrm{a}$ \\
\hline
\end{tabular}

1 


\section{Table 3(on next page)}

Correlation analyses between diversity indices and soil properties.

* and ** represent significance $(P<0.05$ and $P<0.01)$ of soil samples according to Pearson's correlation analysis. 


\begin{tabular}{ccccccccccc}
\hline & Diversity & $\mathbf{p H}$ & $\mathbf{O M}$ & $\mathbf{T N}$ & $\mathbf{A N}$ & $\mathbf{T P}$ & $\mathbf{A P}$ & TK & AK & Salt \\
\hline \multirow{6}{*}{ Fungi } & Shannon & 0.461 & 0.124 & -0.635 & $-0.721^{*}$ & -0.396 & $-0.834^{* *}$ & -0.119 & -0.17 & -0.398 \\
& Simpson & -0.611 & 0.004 & 0.627 & $0.822^{* *}$ & 0.444 & $0.803^{* *}$ & 0.238 & 0.364 & 0.547 \\
& Ace & 0.181 & 0.409 & -0.458 & -0.261 & -0.115 & -0.526 & 0.042 & 0.214 & 0.069 \\
& Chao & 0.147 & 0.419 & -0.467 & -0.238 & -0.127 & -0.54 & 0.101 & 0.238 & 0.106 \\
\hline \multirow{6}{*}{ Bacteria } & Shannon & 0.509 & 0.093 & -0.588 & -0.652 & $-0.670^{*}$ & $-0.769^{*}$ & 0.005 & -0.103 & -0.305 \\
& Simpson & 0.034 & 0.256 & -0.485 & -0.261 & -0.047 & -0.169 & -0.221 & -0.073 & -0.072 \\
& Ace & 0.596 & 0.317 & -0.586 & -0.627 & $-0.738^{*}$ & $-0.736^{*}$ & 0.12 & 0.039 & -0.14 \\
& Chao & $0.672^{*}$ & 0.297 & -0.655 & $-0.736^{*}$ & $-0.742^{*}$ & $-0.787^{*}$ & -0.034 & -0.03 & -0.262 \\
\hline
\end{tabular}

1 


\section{Table 4 (on next page)}

Major topological properties of the single factor association networks of fungal and bacterial communities.

The number of original OUTs was used for network construction by random matrix theory (RMT)-based approach. Network size was the number of nodes in the network. Network diameter was the maximum distance between any two nodes in the network. Transitivity was the probability that two connected nodes of the same node were still connected to each other. 


\begin{tabular}{ccccccccc}
\hline & $\begin{array}{c}\text { Number } \\
\text { of } \\
\text { original } \\
\text { OUTs }\end{array}$ & $\begin{array}{c}\text { Network } \\
\text { size }\end{array}$ & $\begin{array}{c}\text { Number } \\
\text { of genus }\end{array}$ & $\begin{array}{c}\text { Network } \\
\text { diameter }\end{array}$ & Transitivity & $\begin{array}{c}\text { Average } \\
\text { connect }\end{array}$ & $\begin{array}{c}\text { Average } \\
\text { clustering } \\
\text { coefficient }\end{array}$ & $\begin{array}{c}\text { Average } \\
\text { path } \\
\text { distance }\end{array}$ \\
\hline Fungi & 400 & 220 & 25 & 4 & 0.70 & 4.4 & 0.67 & 1.86 \\
Bacteria & 400 & 320 & 25 & 4 & 0.82 & 6.4 & 0.79 & 1.57 \\
\hline
\end{tabular}

1 


\section{Figure 1}

Locations of the rhizosphere soils from Fritillaria ussuriensisin different health levels.

Sampling point was located in Hailin Forestry Farm, Hailin City, Mudanjiang City, Heilongjiang Province, China. The healthy samples were located at 44.8935 north latitude and 129.3155 east longitude; the pathology sample was located at 44.8891 north latitude and 129.3163 east longitude; the blank sample was located at 44.8888 north latitude and 129.3159 east longitude. 


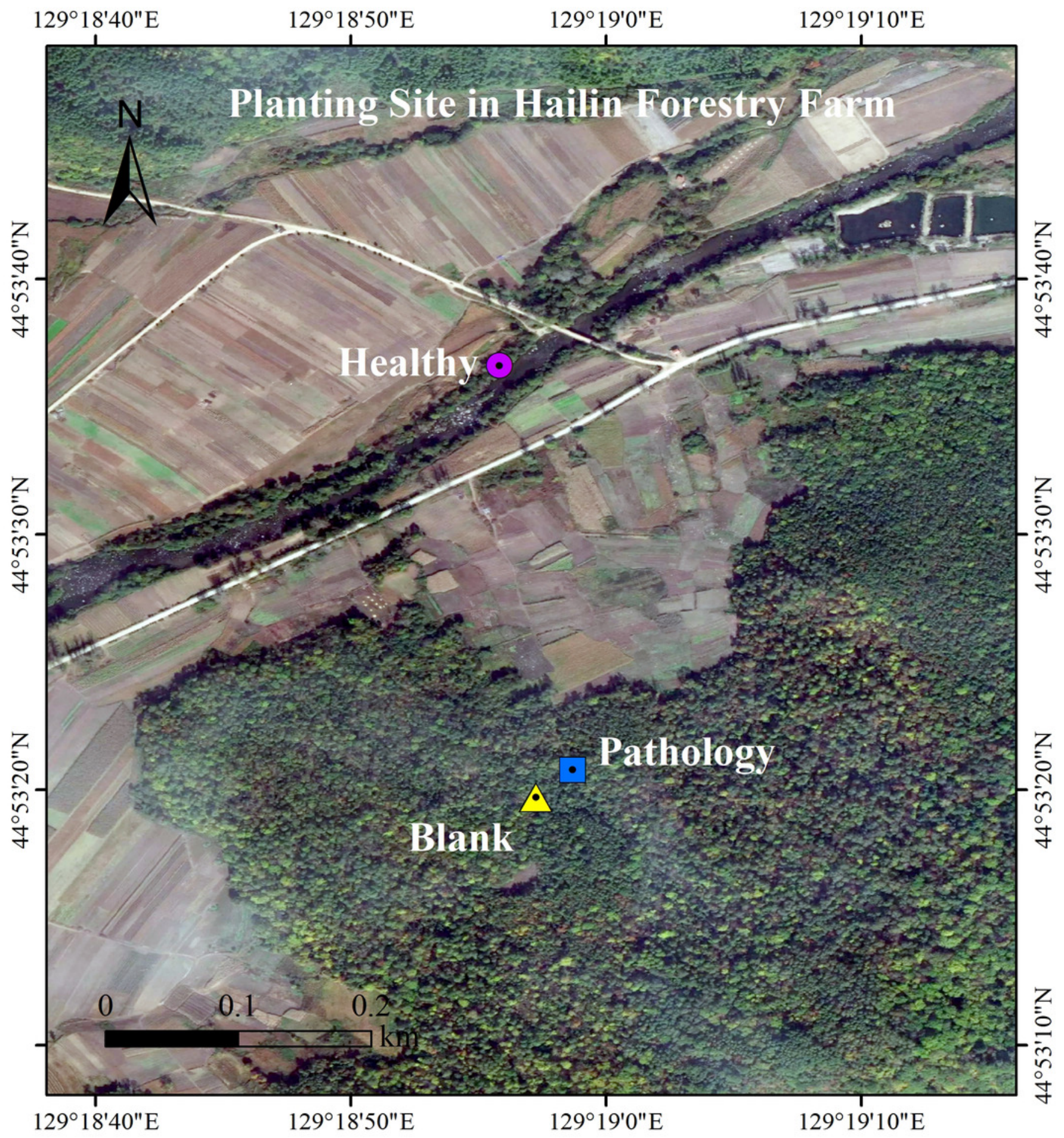


Figure 2

Planting survey plot of Fritillaria ussuriensis in different health levels. 


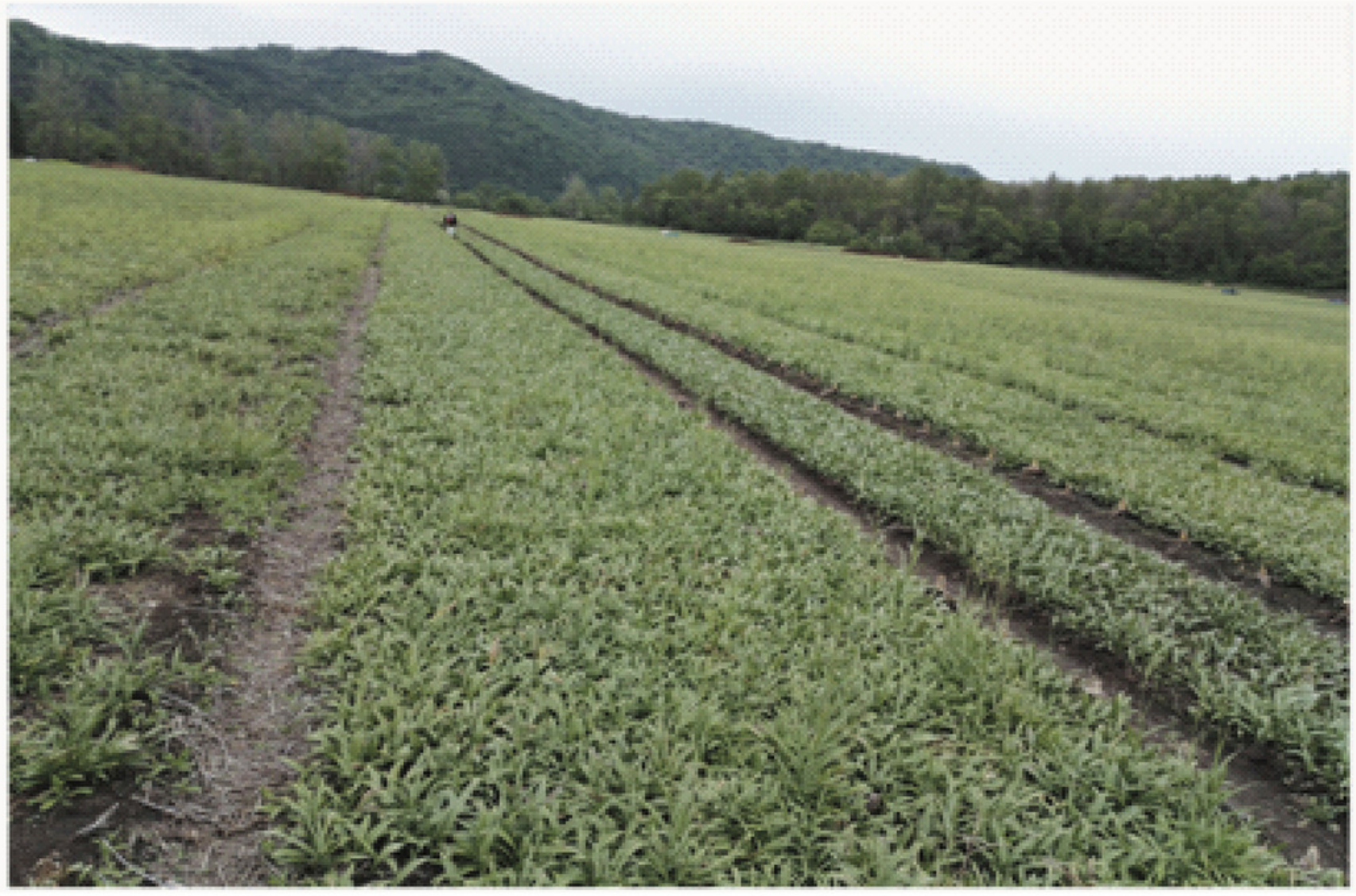

\section{Planting survey plot of Fritillaria ussuriensis}

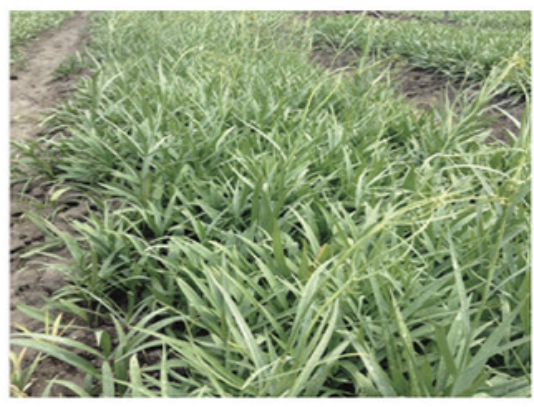

Healthy

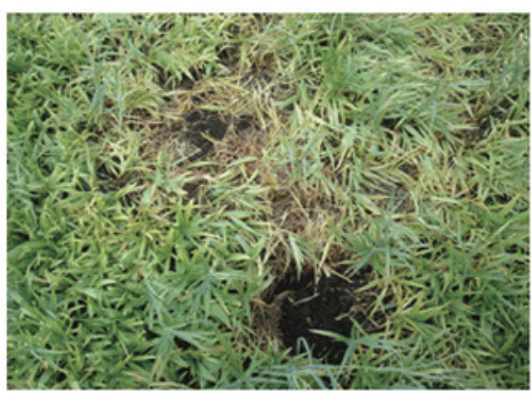

Pathology

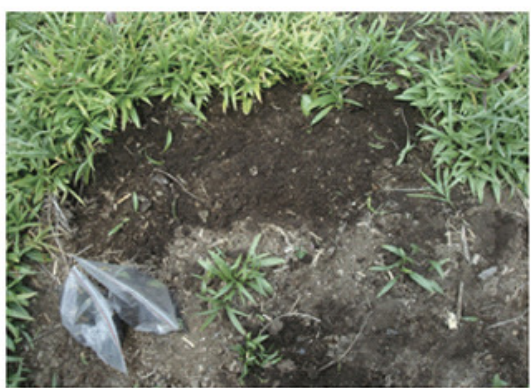

Blank 


\section{Figure 3}

Venn diagram showing the shared operational taxonomic units (OTUs) of Healthy, Pathology and Blank.

The Column chart shows the size of each list and the Bar chart shows the number of single or multiple elements.

\section{Fungi}

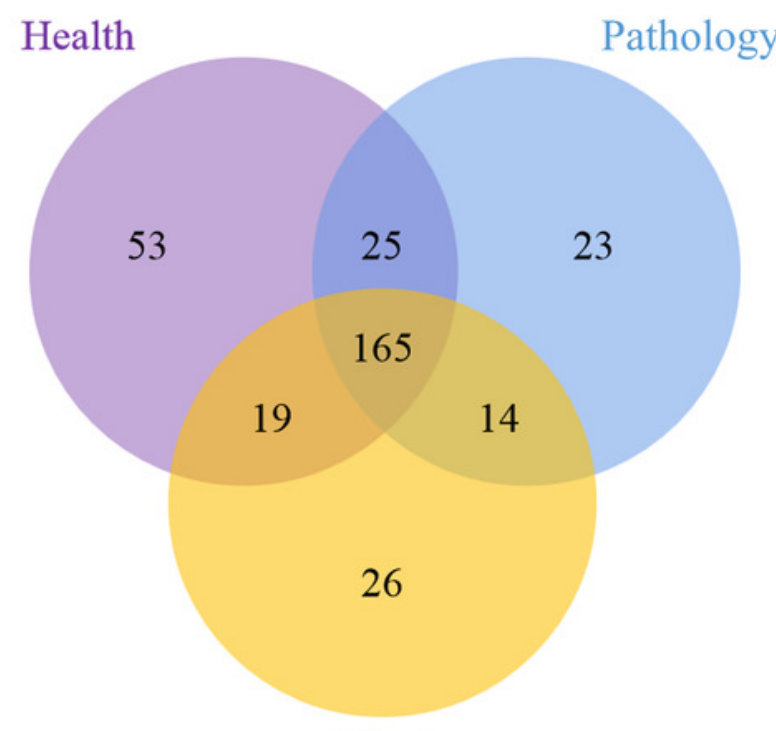

Blank

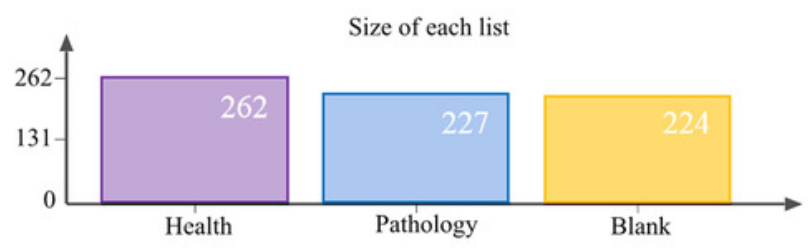

Number of elements: specific (1) or shared by $2,3, \ldots$ lists

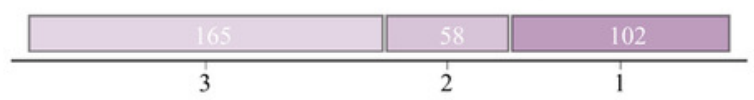

Bacteria

Health

Pathology

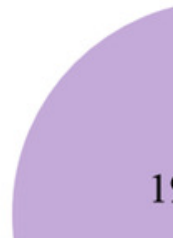

19

20

3

522

25

30

13

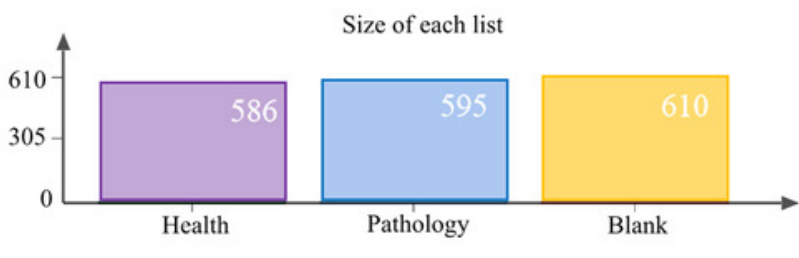

Number of elements: specific (1) or shared by $2,3, \ldots$ lists

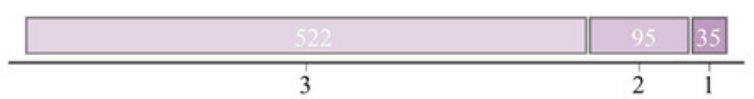


Figure 4

Principle coordinate analysis ( $\mathrm{PCOA}$ ) of fungal and bacterial communities structures in Healthy, Pathology and Blank.

Fungi

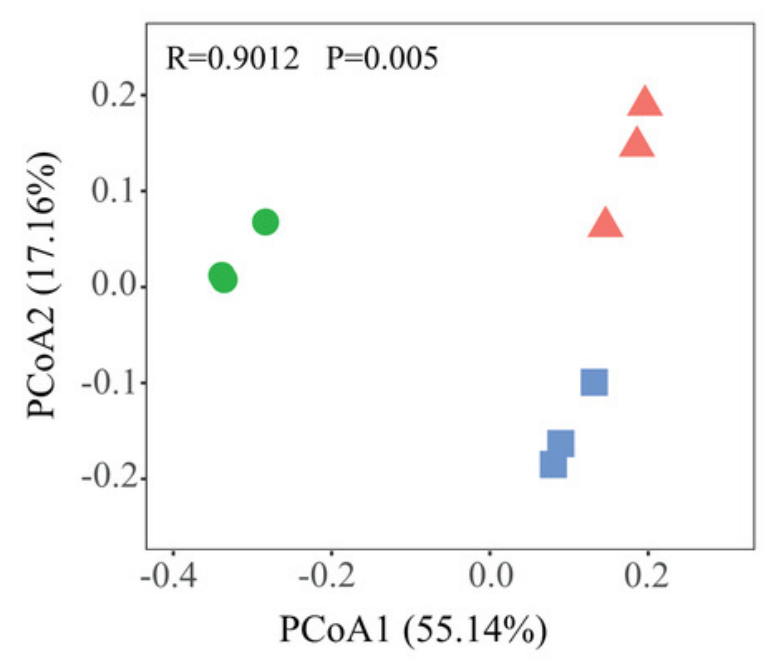

Bacteria

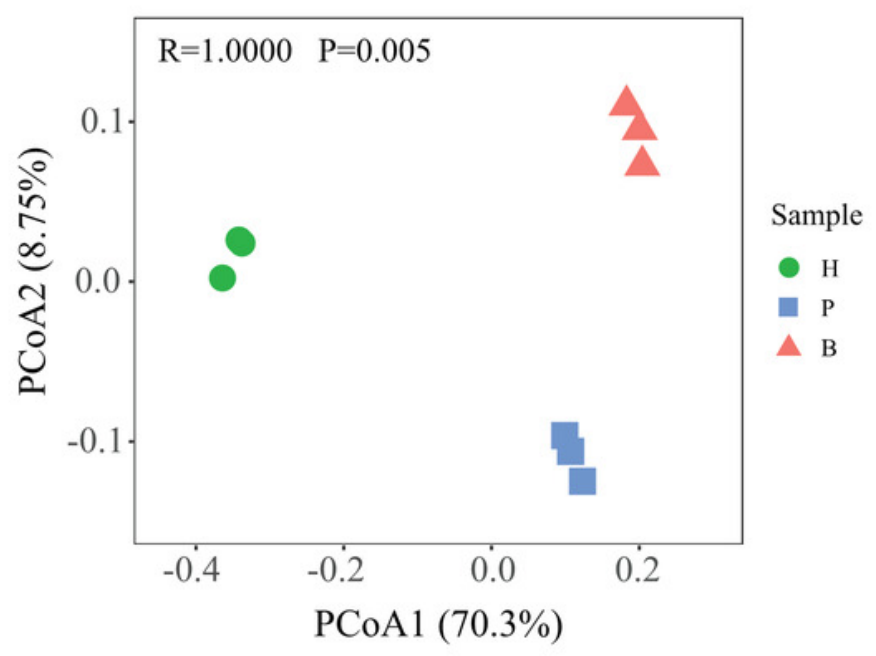




\section{Figure 5}

Relative abundances of the main fungal and bacterial phyla of the rhizosphere soil in Healthy, Pathology and Blank.

The "Others" and "Unclassified_k_Fungi" comprised the unclassified and low-abundance phyla $(\mathrm{RA}<0.1 \%)$.

\section{Fungi}

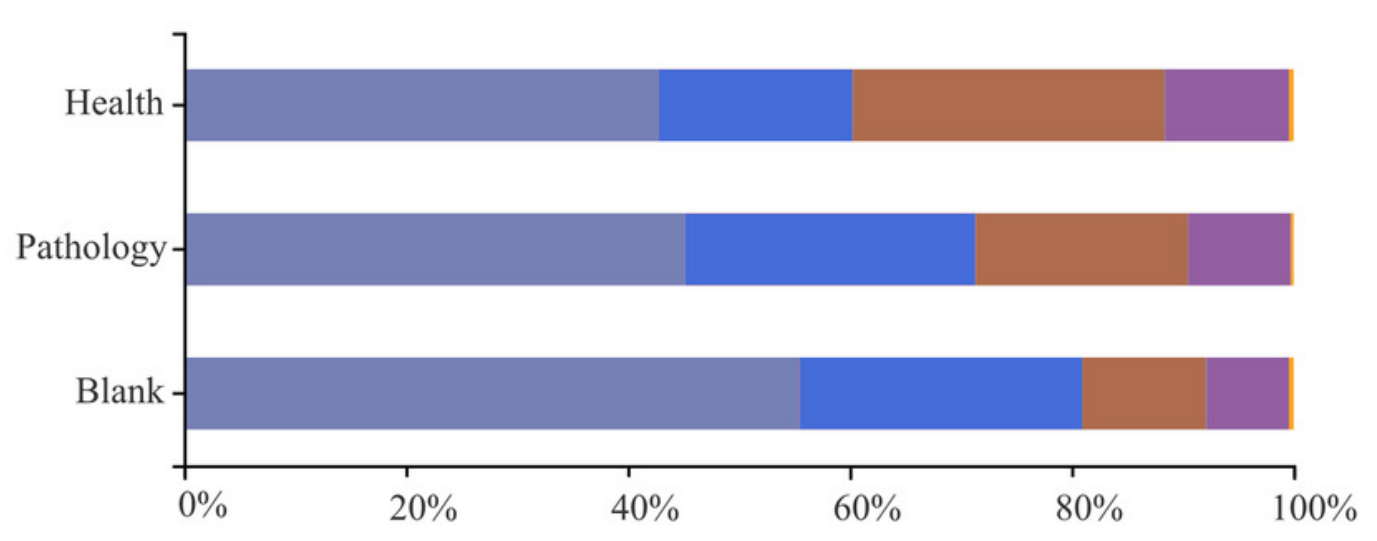

Ascomycota

Mortierellomycota

Basidiomycota

—unclassified_k_Fungi

others

\section{Bacteria}

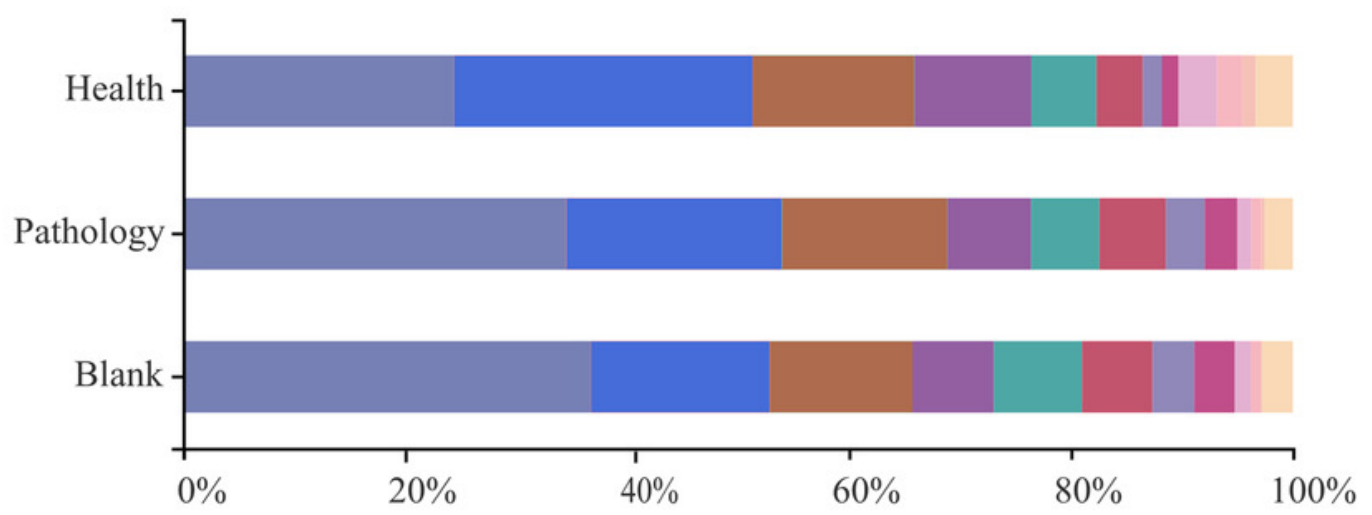

Relative abundance 
Figure 6

Relative abundances of the top 7 fungal genera and top 15 bacterial genera of the rhizosphere soil in Healthy, Pathology and Blank.

Different letters represent significance $(P<0.05)$ of the genus levels in different health levels according to Duncan's new multiple range test. 


\section{Fungi}

\section{Bacteria}

Sphingomonas

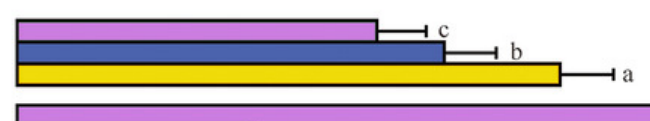

RB41

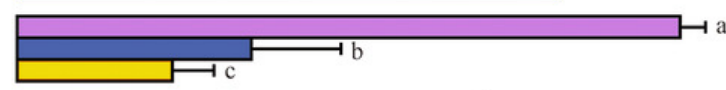

Arthrobacter

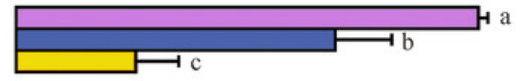

Bryobacter

Gemmatimonas
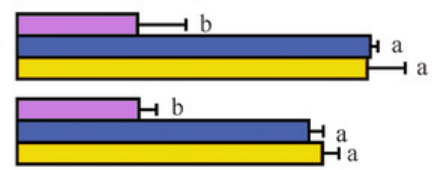

Bacillus

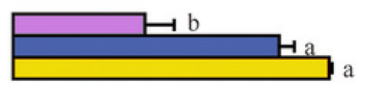

\section{Ellin6067}

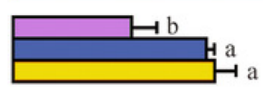

Pedobacter

$$
\square \mathrm{H} \mathrm{b}
$$

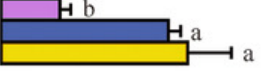

Pseudolabrys

Pseudomonas

$$
\square \longrightarrow c
$$
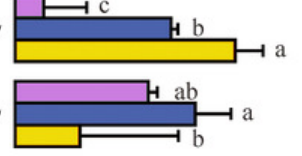

Massilia

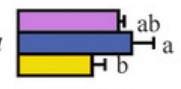

Haliangium

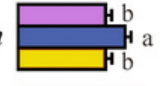

MNDI

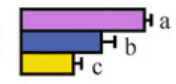

Acidothermus

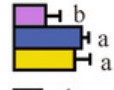

Acidibacter
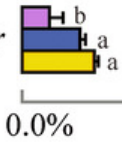

$0.0 \%$

$$
\text { 年 }
$$

$\begin{array}{lll}1 & 1 & 1 \\ 1.5 \% & 3.0 \% & 4.5 \%\end{array}$

Relative abundance
Pvalue

0.003756

0.007322

0.000838

0.014960

0.001105

0.000106

0.002019

0.035120

0.004400

0.004023

0.003990

0.000307

0.002656

0.012480

0.001080

0.006476

0.101000

0.037630

0.036360

0.004545

0.048640

0.005848 


\section{Figure 7}

Correlation heatmaps between community composition of soil fungi and bacteria composition and environmental factors.

$*, * *$ and $* * *$ represent significance $(P<0.05, P<0.01, P<0.001)$ of soil samples according to Pearson's correlation analysis. 


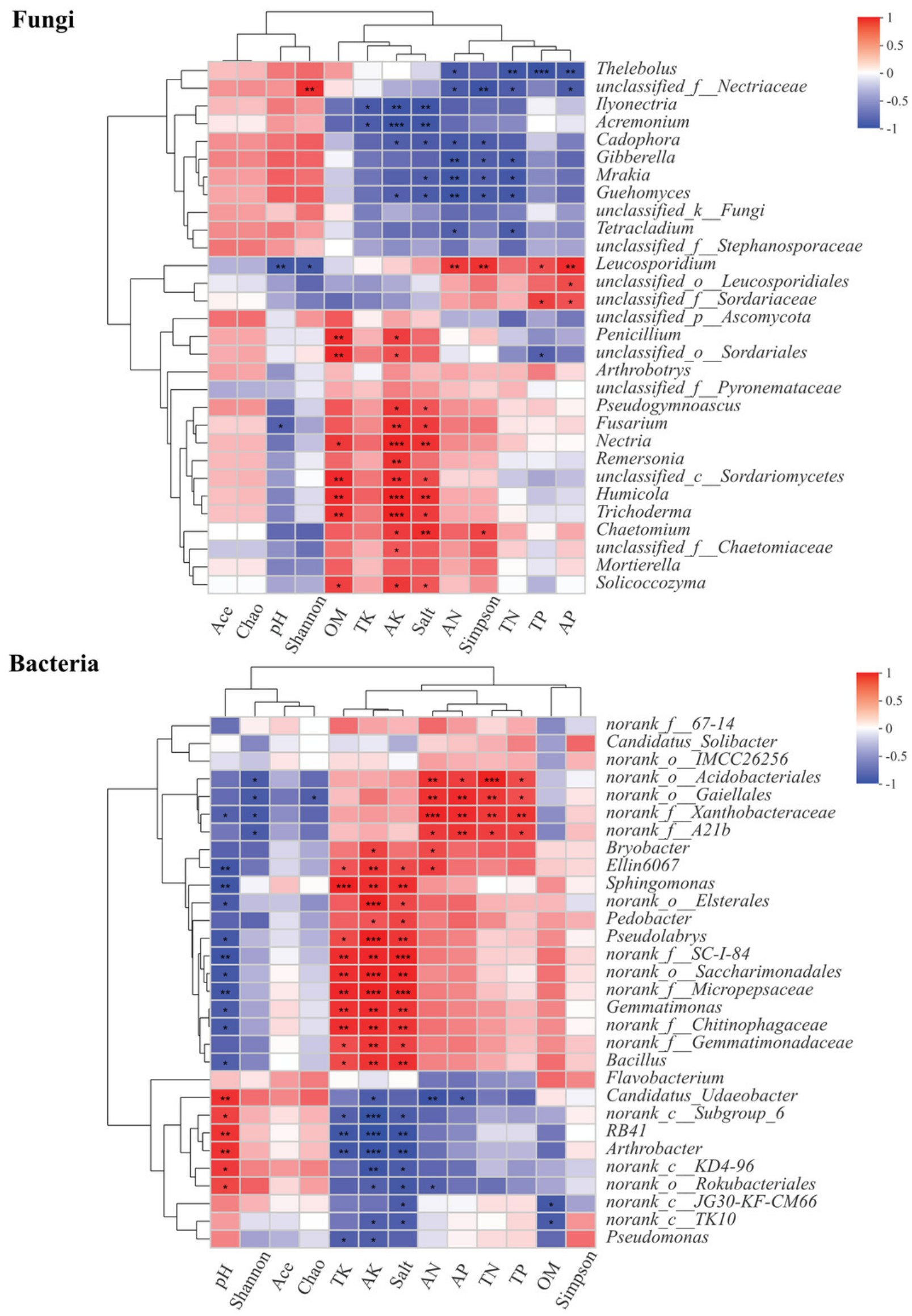


Figure 8

Single factor co-correlation networks of fungal and bacterial communities.

The color of the dot in network diagram indicated the phylum category, the size of the dot indicated the abundance of genera, the red line indicated the positive correlation, the blue line indicated the negative correlation, and the thickness of the line indicated the degree of genera correlation.
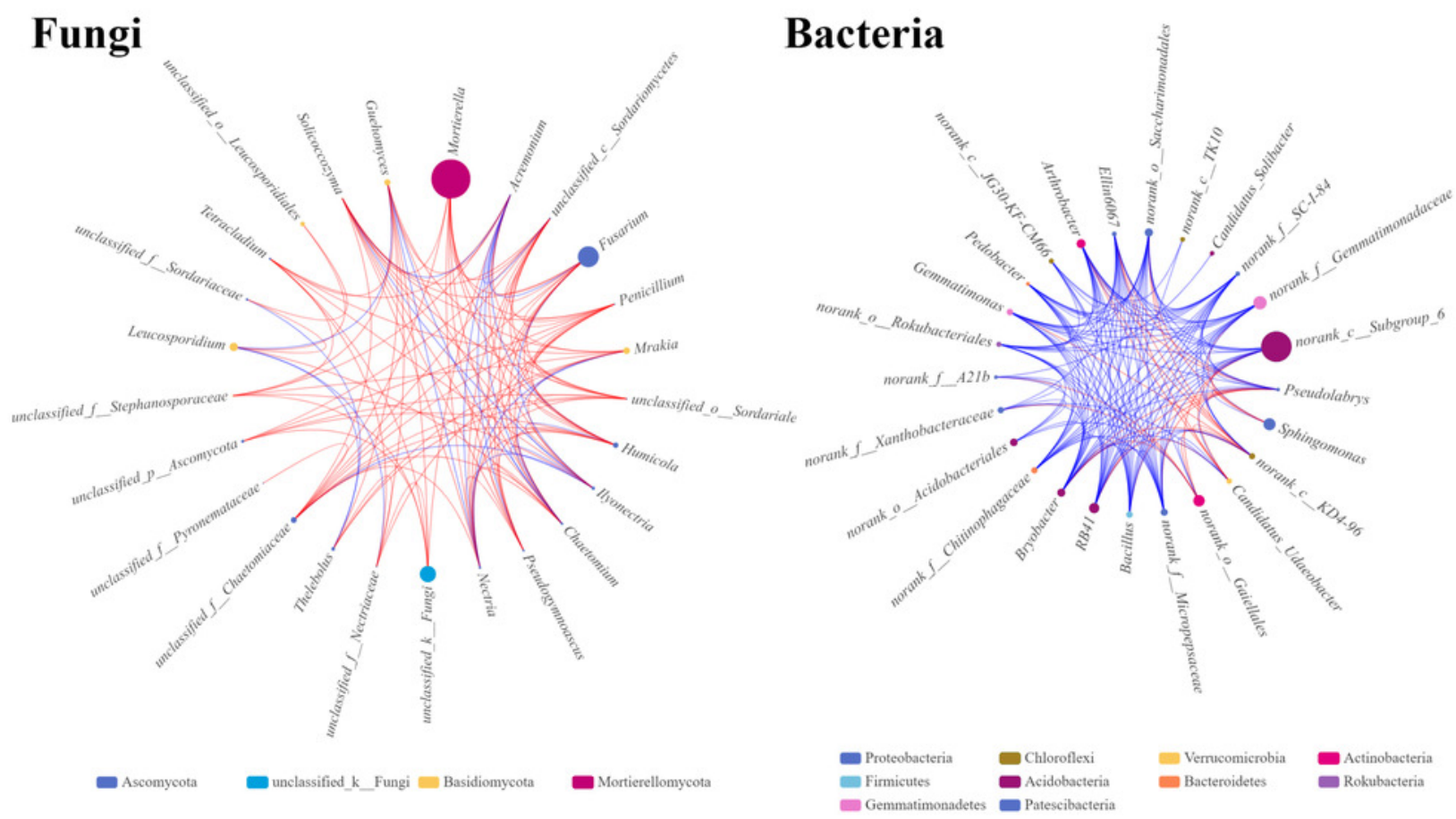